Author version: Biofouling, vol.27(3); 2011; 241-254

\title{
Effect of chlorination on the development of marine biofilms dominated by diatoms
}

\author{
Jagadish S. Patil ${ }^{*}$ V. Jagadeesan \\ National Institute of Oceanography (Council of Scientific and Industrial Research) \\ Dona Paula 403 004, Goa, India
}

Tel: 91(0)832-2450 513; Fax: 91(0)832-2450 615

*corresponding author: patilj@nio.org; Tel: 91(0)832-2450 513; Fax: 91(0)832-2450 615

\begin{abstract}
This study addressed the antifouling efficiency of commercially available chlorine at different concentrations $(0.5 \%, 1 \%$ and $2 \%)$ and exposure time $(0.5 \mathrm{~min}, 1 \mathrm{~min}, 5 \mathrm{~min}$ and $15 \mathrm{~min})$. The rapid and non-destructive FIRe (fluorescence induction and relaxation) technique was used to evaluate the effects of the biocide on diatom dominated biofilms. The efficiency of chlorine in removing diatoms from the developed biofilms increased with an increase in concentration and exposure time. The fluorescence measurements revealed low $F_{\mathrm{v}} / F_{\mathrm{m}}$ and high $\sigma_{\mathrm{PSII}}$ values for chlorine-treated Navicula and Amphora biofilms indicating that chlorination was efficient in damaging the photosystem-II reaction centers. Chlorination also caused mortality of diatom cells by damaging the cell body. In natural biofilms, the biocidal effect of chlorine was species specific; species of Amphiphrora, Navicula, Cylindrotheca and Coscinodiscus showed an increase in the density of the population, but species of Pleurosigma, Amphora and Thalassionema did not increase in density after chlorine treatment. It was also demonstrated that diatoms can colonize, grow and photosynthesize on chlorine treated surfaces. Under pulse chlorination (treatment every 6h) irrespective of chlorine concentration, the development of biofouling decreased with an increase in exposure time. Differences between exposure times of 1-15 min were not significant. Additionally, transmission levels of the control (non-chlorine-treated) fouled coupons reduced significantly $(\sim 20 \%)$ compared to the chlorine-treated fouled coupons $(<2 \%)$. These results suggest that chlorine can be used as a biocide to control the development of diatom biofilms.
\end{abstract}

Key words: diatoms, biofilms, chlorine, FIRe, pulse chlorination 


\section{Introduction}

Marine and freshwater biofouling is one of the major unsolved problems currently affecting the shipping industry and industrial equipment. The term 'biofouling' refers to the undesired accumulation of microorganisms, plants and animals on any artificial structures, which are exposed to aquatic environments. The establishment of fouling communities on a wide variety of substrata has been investigated thoroughly and the resulting literature is vast. The establishment of the fouling community has been characterized in terms of several stages and some of these stages can overlap or occur in parallel (Railkin 2004). In the development of biofouling, any submerged surface rapidly becomes coated by a conditioning film comprising of organic and inorganic molecules (Loeb and Neihof, 1975; Bakker et al. 2003; Bhosle et al. 2005; Jain and Bhosle 2009) which may act as source of nutrients for microrganisms. Formation of this film is immediately followed by an accumulation of microorganisms (bacteria, diatoms), which secrete extracellular polymeric substances (EPS) during attachment, colonisation, and population growth and the resulting layer is termed as the biofilm (microfilm). The biofilm may moderate the settlement of larvae of higher organisms such as barnacles, mussels and tubeworms which constitute macrofouling (Dobretsov et al 2006; 2009). These organisms cause serious technical problems by settling on shiphulls, power plant cooling systems, aquaculture systems, fishing nets, pipelines, submerged structures and also oceanographic research instrumentation thereby leading to huge economic losses (see Schultz et al. for economic analysis of fouling on ships).

Disinfecting agents such as ultraviolet radiation (UVR) and chlorination were identified as the promising new biofouling control methods during the workshop "Biofouling Prevention Technologies for Coastal sensors/Sensor platform", although further development in this direction is required (ACT report 2003). The antifouling efficiency of UVR in the prevention of marine biofouling has been reported (Patil et al. 2007; Lakretz et al. 2009, Bak et al. 2010a, 2010b). In the present investigation, the efficiency of chlorine, ie concentration and exposure time, in controlling the development of marine biofilms is addressed. Chlorination is a widely accepted method for control of biofouling in cooling systems employing seawater and freshwater. The effects of chlorine on the metabolic and physiological processes of microorganisms, especially bacteria in drinking water are well known. Chlorine affects bacteria by causing damage to cell membranes, proteins and nucleic acids (Saby et al. 1997; Phe et al. 2004, 2005). There are also reports that microalgae may suffer damage from chlorine stress arising from power plant discharge (Poornima et al. 2005; Nancharaiah et al. 2007). However, there are no detailed 
investigations that have explored the application of chlorination to control marine biofilms dominated by diatoms. Furthermore, the biofilm literature has a different focus to the research described herein. Diatoms are the earliest eukaryotic colonizers of submerged surfaces and one of the most conspicuous organisms in biofilms. Diatoms attach to the substratum by secretion of EPS (Wetherbee et al. 1998; Molino and Wetherbee 2008), and contribute significantly to the biofilm (Patil and Anil 2005). In this study chlorine treatment was given as pulses every $6 \mathrm{~h}$ in order to obtain optimal antifouling efficacy with a minimal amount of chlorine.

\section{Materials and Methods}

The efficiency of chlorine in controlling the development of biofouling was evaluated by conducting a series of experiments in the laboratory using natural sea water and cultures of common fouling diatoms.

\section{Experiment 1. Effect of chlorine on the growth of biofilm diatoms}

Altogether three separate experiments were conducted to evaluate the effect of different concentrations and exposure times of commercially available chlorine viz. sodium hypochlorite solution containing $4 \%$ $(\mathrm{w} / \mathrm{v})$ available chlorine. For the experiments, 0.5 and $1 \%$ chlorine (w/v) and exposure times of 1 and 5 min were selected. Two experiments were conducted using monoalgal cultures of diatoms dominant in biofilms (Amphora coffeaeformis and Navicula transitans var. derasa f. delicatula) and the other experiment was conducted using natural biofilms. Cultures of Amphora and Navicula were maintained in the National Institute of Oceanography, Goa, India. These diatoms were originally isolated from benthic biofilms in Dona Paula Bay, west coast of India (15 $\left.27^{\prime} \mathrm{N}, 73^{\circ} 48^{\prime} \mathrm{E}\right)$. Cultures were maintained in exponential growth phase by weekly re-inoculation into fresh culture medium, prepared in autoclaved seawater ( $\sim 35 \mathrm{psu}$ ) enriched with $\mathrm{f} / 2$ nutrients (Guillard and Ryther 1962). Cells were grown in Erlenmeyer flasks $(100 \mathrm{ml})$ containing $50 \mathrm{ml}$ of culture medium and were maintained at $20 \pm 1{ }^{\circ} \mathrm{C}$ under a photocycle of 12:12 h light:dark.

For each experiment, 15 microscopic cover glasses $(18 \mathrm{~mm})$ and polytstyrene multiwells (6 well) were used to develop diatom biofilms. Each cover glass was placed in a single well of the multiwell containing $\sim 4.5 \mathrm{ml}$ of sterile $\mathrm{f} / 2$ medium. Diatom stocks $(\sim 0.5 \mathrm{ml})$ were added and then the wells were incubated as above. In the case of monospecies experiments, 10,000 cells were added to each well, whereas for natural biofilms a concentrated 'soup' of natural seawater was used. After incubation for 1 
week, 12 cover glasses were used for chlorine treatment and the remaining 3 cover glasses were used as experimental controls. For each treatment, 3 replicates were used.

Prior to chlorine treatments all the cover glasses with biofilms were observed microscopically (20x objective) and photographed (3 fields of view for single species biofilms and 10 fields of view for natural biofilms based on homgenous and heterogenous distribution in single and multispecies biofilms) for initial observations (cell counts and integrity) using an inverted microscope (Olympus IX2-ILL-100) equipped with a digital camera. Cells with intact chloroplasts were considered as live cells. After initial observation, cover glasses ( 3 replicates per treatment) with biofilms were treated with chlorine $(0.5 \%$ and $1 \%$ ) for either $1 \mathrm{~min}$ or $5 \mathrm{~min}$. After chlorination, the biofilms were dip rinsed in filtered seawater to remove excess chlorine. The control biofilms were subjected to similar treatment with filtered sea water (no chlorine) to reproduce any handling effects. The chlorine-treated and control biofilms were transferred into new polystyrene multiwells ( 6 well plates) containing sterile $\mathrm{f} / 2$ media and incubated for 5 days as described above. Before and after incubation, the chlorine-treated and control biofilms were observed microscopically and photographed.

\section{Experiment 2. Effect of chlorine on algal biomass, photosynthetic parameters, exopolysaccharide (EPS) and cell structure of fouling diatoms}

Experiments were also conducted to evaluate the effect of chlorine on algal biomass, concentration of exopolysaccharide (EPS) and cell structure. These experiments were performed separately and were carried out immediately after chlorine treatment. The experimental set-up for chlorine treatment was as described above. Algal biomass, EPS concentration and cell structure were measured by estimation of chlorophyll concentration, fluorescent transients by a fluoroscence induction and relaxation technique, alcian blue staining and imaging microscopy. Imaging of alcian blue stained biofilms, chlorophyll fluorescence and cell structure was carried out by light microscopy (LM), epifluorescence microscopy (EM) and scanning electron microscopy (SEM), respectively.

\section{Chlorophyll analysis}

The chlorophyll (chl a) concentration of chlorine-treated and control biofilms (mono-species and natural community) in duplicate, was estimated by extraction in $90 \%$ acetone. The biofilm from each cover glass was removed with a nylon brush into a sterile Petri dish with $10 \mathrm{ml}$ of filtered seawater, which was 
then filtered through GF/F Whatman filter paper (Patil and Anil 2005a, b). The filters were immediately used for chl $a$ analysis in a fluorometer (Turner designs, Trilogy).

\section{Photosynthetic parameters}

The application of the fluorescence induction and relaxation (FIRe) technique is demonstrated for the first time to study the effect of biocides on diatom biofilms. The method is rapid and non-destructive. The status of chlorophyll in chlorine-treated monospecies biofilms (Amphora and Navicula) was further assessed using the FIRe technique. The FIRe fluorometer measures a suite of photosynthetic parameters such as initial $\left(F_{0}\right)$, maximum $\left(F_{\mathrm{m}}\right)$ and variable $\left(F_{\mathrm{V}}=F_{\mathrm{m}}-F_{0}\right)$ components of photosystem II (PSII) fluorescence, quantum yield $\left(F_{\mathrm{V}} / F_{\mathrm{m}}\right)$ and functional absorption cross-section ( $\left.\sigma \mathrm{PSII}\right)$, which can be used to assess the physiological status of the photosynthesizing organisms such as diatoms. If chlorine treatment has damaged chl $a$ or detached it from the photosystem II (PSII) reaction center, then initial fluorescence $\left(F_{0}\right)$ is affected and no fluorescence transient takes place. In this case $F_{v}$ will be very low. The fluorescence transients were measured using a FIRe fluorometer (Satlantic Inc.) equipped with a fiber optic probe. Prior to measurements, the biofilms were dark adapted for $30 \mathrm{~min}$. The gain was adjusted depending upon the chl $a$ concentration of the sample taken for measurement. Curves were fitted using the FIRePro software.

\section{Alcian blue staining}

In order to confirm whether chlorine was effective in removing diatom EPS from the biofilm, alcian blue staining was performed on chlorine-treated and control biofilms of Amphora and Navicula. Biofilms were incubated with $500 \mu 1$ of freshly prepared dye for 30 minutes in darkness. Excess stain was removed by dip rinsing with filtered sea water. The stained biofilms were observed under an Olympus microscope equipped with image analysis.

\section{Scanning Electron Microscopy (SEM)}

SEM was used to evaluate the effect of chlorine on cell structure. Biofilms were air dried and mounted on stubs followed by gold-coating and examination at $15 \mathrm{kV}$ with a JEOL JSM-5800 LV scanning electron microscope. 


\section{Experiment 3. Influence of algal seeding on the development of chlorine-treated biofilms}

To evaluate the influence of algal seeding on the development of chlorine-treated biofilms, experiments were conducted with Navicula and Amphora. The experimental set-up was as described above, but the chlorine-treated biofilms were incubated in f/2 medium containing $\sim 2750$ cells. The chlorine-treated and control biofilms were observed microscopically and photographed before and after the incubation period of 3 and 7 days. In addition, photosynthetic parameters were measured as above using a FIRe fluorometer.

\section{Experiment 4. Effect of pulse chlorination on the development of natural biofilms}

Three experiments were conducted to evaluate the effect of chlorine concentration and exposure time on biofouling development. In order to develop multispecies biofilms, clean glass slides were deployed in a tank containing natural seawater enriched with $\mathrm{f} / 2$ nutrients. The first experiment was initiated by using $0.5 \% \mathrm{w} / \mathrm{v}$ chlorine (commercially available sodium hypochlorite solution). In this experiment the deployed glass coupons (10 replicates were used for each exposure time) were exposed for different times $(0.5,1,5$ and $15 \mathrm{~min})$ to $0.5 \%$ chlorine every 6 hours for a period of 15 days. The glass coupons were retrieved and treated with chlorine every 6 hours. Before replacing the glass coupons in the tank, the chlorine-treated coupons were dip rinsed three times in filtered sea water to remove any residual chlorine. Controls were glass coupons not exposed to chlorine treatment $(0 \mathrm{~min})$. During the course of the experiments, water in the tank was continuously stirred to minimize sedimentation of particles. The seawater in the tank was also changed every 3 days with enriched natural seawater to provide fresh nutrients and fouling inoculum. On the $15^{\text {th }}$ day, glass coupons (10 each for each exposure time) were recovered. Five glass coupons for each from each exposure time ie 0.5, 1, 5 and 15 min were used for chl $a$ analysis by extraction in 90\% acetone. For chl $a$ analysis, biofilms were removed as described above into $25 \mathrm{ml}$ of filtered seawater, which was then filtered onto GF/F Whatman filter paper (Patil and Anil 2005a and b). The filter papers were immediately used for chl $a$ analysis in a fluorometer.

The remaining glass coupons were used to measure biofilm transmission spectra and buildup of biofouling. Prior to drying, the recovered coupons were immediately dip rinsed in $0.2 \mu \mathrm{m}$ sterile filtered seawater to remove loosely attached particles. The transmission measurement of treated and control glass coupons was assessed (10 fields of view) by using microscopy (10x objective) and Image pro software. Prior to measurement, the coupons (5 replicates per treatment) were air-dried as described in 
Patil et al. (2007). A clean, dried and unsubmerged glass coupon was used as the reference (100\%). After the measurements, test coupons were further dried at $50^{\circ} \mathrm{C}$ till constant weight was attained to determine total weight of biofouling $\left(\mathrm{mg} \mathrm{coupon}^{-1}\right)$. Weight was calculated from the difference in weight of the coupon prior to and after immersion. The above experiment was repeated twice by using $1 \%$ and $2 \%(\mathrm{w} / \mathrm{v})$ chlorine.

\section{Data Analyses}

Uniformity between the data sets was achieved by normalizing the data obtained for weight of biofouling, chlorophyll $a$ and cell abundance to the respective controls. The effectiveness of chlorine treatments (concentrations and exposure times) on diatom biofilms (Amphora, Navicula and natural biofilms) was assessed by analysis of variance (ANOVA) followed by post hoc Tukey's multiple comparison test $(\alpha=0.05)$. ANOVA and Tukey's multiple comparison tests were performed by using Statistica (StatSoft) software package.

Two-way ANOVA followed by Tukey's multiple comparison test was used to evaluate the effect of chlorine on growth (after incubation in fresh medium) as well as to assess whether there were significant increments in the diatom biofilm population on chlorine-treated monospecies biofilms. Chlorophyll $a$ data was also subjected to one-way ANOVA followed by Tukey's multiple comparison test to evaluate significant differences between treatments.

The results of the pulse chlorination experiments (normalized data for biofouling buildup and biofilm chlorophyll $a$ ) were also subjected to one-way ANOVA with replication followed by Tukey's multiple comparison test as described above. These analyses were performed to evaluate the effect of exposure time at different chlorine concentrations as well as to evaluate the differences within the treatments. In later analyses, chlorine exposure time and concentration were considered as separate variables. These data were analyzed further using cluster analysis, to determine the most efficient combination of chlorine concentration and exposure time using PRIMER software (version 5). 
Results

\section{Effect of chlorine on the growth of fouling diatoms}

Results of the experiment to evaluate the effect of chlorine on diatoms as well as on their growth are presented in Table 1 and Figure 1. After chlorine treatment, the density of diatoms in both monospecies and multi-species biofilms decreased when compared with control coupons (Table 1). This was confirmed from the significant differences (2-way ANOVA, $\mathrm{p}<0.001$ ) observed in cell abundance between the chlorine-treated and control glass coupons (Table 2). Maximum cell abundance was always observed in the control samples. Tukey's multiple comparison tests revealed that the differences between control and chlorine treated biofilms (for Amphora, Navicula and natural biofilms) was significant (Table 2). Tukey's test also revealed that in the case of Amphora and natural biofilms, the differences among the chlorine treatments were not significant (Table 2). In addition, in the case of Navicula, the differences between both the exposure times at each of the $0.5 \%$ and $1 \%$ chlorine concentrations were not significant. However, significant differences were observed between the $0.5 \%$ and $1 \%$ chlorine concentrations at each exposure times (Table 2). After normalizing against the control $(100 \%)$, it was observed that in the case of Navicula, Amphora and natural biofilms, the decrease in cell densities was $67 \%, 64 \%$ and $40 \%$, respectively. This indicates that among the chlorine treatments, the efficiency of chlorine in removing the diatoms from the developed biofilms increased with the increase in chlorine concentration and exposure time (Figure 1).

In order to evaluate the growth of chlorine-treated diatom cells, the chlorine-treated diatom biofilms and control coupons were incubated for a period of 5 days and the results are presented in Table 1 and Figure 1. It was observed that an increase in the diatom population and variable fluorescence $\left(F_{v}\right)$ was not observed in mono-species biofilms, whereas in case of natural biofilms, a population increase was observed for all of the chlorine treatments (Table 1 and Figures 1 and 5). TwoANOVA revealed that the differences in the populations of diatoms in biofilms before and after incubation was significant (Table 5). This was observed in monospecies (Amphora and Navicula) biofilms as well as natural biofilms (Table 2). In natural biofilms, the increase in the population was due to the increase in the abundance of particular diatom species such as Amphiprora sp., Navicula spp., Cylindrotheca closterium and Coscinodiscus sp. (Table 3). Species of Pleurosigma, Amphora and 
Thalassionema showed no increase in abundance after incubation (Table 3). These observations indicate that the biocidal effect of chlorine was species specific.

\section{Effect of chlorine on chlorophyll, photosynthetic parameters, exopolysaccharide (EPS) and cell structure of fouling diatoms}

The results of the experiments to evaluate the effect of different chlorine concentrations and exposure times of chlorine on chlorophyll, photosynthetic parameters, exopolysaccharide (EPS) and cell structure of fouling diatoms are presented in Figures 2 to 5 .

Epifluorescence microscopy was used to reveal the presence of chlorophyll, which autofluoresces red, in cells. Cells without chlorophyll were considered as dead. Cells on control coupons showed red fluorescence whereas those on the chlorine-treated coupons at all concentrations and exposure times did not show red fluorescence (Figures $2 \mathrm{c}$ and $3 \mathrm{c}$ ). These observations indicate that chlorine damaged the chlorophyll. The results of the chlorophyll analysis of control and chlorine-treated biofilms revealed that chlorine at all concentrations and exposure times resulted in a significant reduction in the biofilm chlorophyll concentrations as compared to control biofilms (Table 4 and Figure 4). One-way ANOVA and Tukey's multiple comparison tests revealed that effect of the chlorine on biofilm chl $a$ (both monospecies and natural biofilms) was significant when compared to controls ( $\mathrm{p}<$ 0.001). The analysis also revealed that among the chlorine treatments, the effect was not significant except in the case of Amphora biofilms wherein chlorine at $0.5 \%$ concentration and a 1 min exposure was less effective when compared to other chlorine treatments (Figure 4). When compared to the respective controls only $1-8 \%$ of chlorophyll was present in the chlorine-treated mono-species biofilms (Navicula and Amphora) whereas it was 2-6\% in the natural biofilms (Table 4 and Figure 4).

The fluorescence measurements using the FIRe fluorometer to assess the status of chlorophyll revealed that the fluorescence values $\left(F_{0}, F_{\mathrm{m}}\right.$ and $\left.F_{\mathrm{v}}\right)$ decreased significantly in chlorine-treated biofilms (at both concentrations and exposure times) compared to the controls (Figure 5), and the quantum yield $\left(F_{\mathrm{v}} / F_{\mathrm{m}}\right)$ decreased accordingly. For both diatoms, $F_{\mathrm{v}} / F_{m}$ values ranged between $035-0.54$ for nontreated biofilms, whereas the values ranged between $0.22-0.26$ for chlorine-treated biofilms (Figure 5). The functional absorption cross-section of PSII ( $\left.\sigma_{\mathrm{PSII}}\right)$ of the normal cells (control) of both Navicula 
and Amphora lies in the range of 300 to 400. The values increased (>500) in chlorine-treated biofilms (Figure 5).

Alcian blue staining revealed that the diatoms (both Amphora and Navicula) in the control biofilms were stained with the dye, whereas the cells present in the chlorine-treated biofilms, at both concentrations and exposure times, did not stain (Figures 2a and 3a). The blue staining was due to the presence of EPS in control biofilms.

Light microscopy observations revealed that chlorine-treated coupons showed the presence of greater number of dead cells compared to control coupons (Table 1 and Figure 1). In the case of Navicula, Amphora and natural biofilms, the percentage of live cells in chlorine-treated coupons was $2 \%$, $0 \%$ and $42 \%$, respectively compared to the respective controls (Figure 1 ).

SEM images revealed that chlorine, at both concentrations and exposure times, was effective in damaging the cell structure of Amphora and Navicula (Figures 2d and 3d).

\section{Influence of algal seeding on the development of chlorine treated biofilms}

The results revealed that chlorine-treated biofilms, when incubated in medium containing fresh culture, showed an increment in the population after of incubation for 3 and 7 days (Table 5 and Figure 6). In case of Navicula biofilms, a $2-6 \%$ and $10-12 \%$ increase in the population was observed on $3^{\text {rd }}$ and $7^{\text {th }}$ day, respectively, whereas in case of Amphora biofilms, a 4-16\% and 10-40\% increase in the population was observed on $3^{\text {rd }}$ and $7^{\text {th }}$ day, respectively. Two-way ANOVA revealed significant differences between chlorine treatments and days of incubation (Table 2). Tukey's multiple comparison tests revealed that the differences between control and chlorine-treated biofilms (both Amphora and Navicula) were significant. In the case of Navicula, among the chlorine treatments, $1 \%$ chlorine at an exposure of $5 \mathrm{~min}$ showed a significant difference compared with the other treatments (Table 2). In the case of Amphora at both exposure times, the effect of 1\% chlorine showed a significant difference compared to that of $0.5 \%$ chlorine (Table 2). The fluorescence measurements of chlorine-treated Navicula and Amphora biofilms also revealed an increase in $F_{\mathrm{v}}$ and $F_{\mathrm{v}} / F_{\mathrm{m}}$ and a decrease in $\sigma_{\mathrm{PSII}}$ values with respect to incubation time (Figure 7). 


\section{Effect of pulse chlorination on the development of natural biofilms}

The experiments to evaluate the effect of chlorine concentration and exposure time on the development of biofouling indicated that in the case of chlorine-treated coupons, biofouling was lower compared to control coupons indicating an inhibitive effect of chlorine (Figure 8). This was confirmed from the significant differences observed in the measurements of biofouling buildup and biofilm chl $a$ between the chlorine treated and non-treated coupons (Figure 8). Maximum biofouling buildup was observed in the control samples. One-way ANOVA revealed that the effect of chlorine at all the concentrations on buildup of biofouling and biofilm chl $a$ was significant between treatments $(\mathrm{p}<0.001)$. Tukey's multiple comparison test revealed that the length of exposure times at all concentrations of chlorine was significant when compared to the control (Figure 8). Among the chlorine treatments at each concentration, biofouling buildup increased with a decrease in exposure time (Figure 8). However Tukey's test also revealed that the effect of exposure time of $15 \mathrm{~min}$ at all concentrations on biofouling buildup and biofilm chl $a$ was also significant when compared with other chlorine treatments (Figure 8). The test also revealed that the effect of exposure time of 1 and $5 \mathrm{~min}$ on biofouling buildup at all concentrations was similar whereas the effect of an exposure time of 0.5 min was not same at all the concentrations (Figure 8). In case of chl $a$, the effect of exposure time $0.5,1$ and 5 min was almost same (Figure 8).

After normalization, the results revealed that the levels of biofouling buildup increased with a decrease in exposure time (Figure 9d). However such a trend was not observed with concentration (Figure 9b). ANOVA revealed that the effect of chlorine at all concentrations and exposure times on biofouling buildup and biofilm chl $a$ was significant between treatments $(\mathrm{p}<0.001)$. Tukey's multiple comparison tests revealed significant differences between chlorine-treated and non-treated biofilms (Figure 9). However, among the chlorine treatments, the effect of concentration was not significant (Figure 9). However, with respect to exposure time, the effect of chlorine on biofouling buildup and chl $a$ declined with a decrease in chlorine exposure time (Figures 9a and c). For chl $a$, Tukey's test revealed that amongst exposure times of $0.5,1$ and $5 \mathrm{~min}$, the differences were insignificant whereas the exposure time of $15 \mathrm{~min}$ showed a significant difference compared to the $0.5 \mathrm{~min}$ exposure (Figure 9). In case of biofouling buildup, the exposure time of 1,5 and $15 \mathrm{~min}$ showed a significant difference with $0.5 \mathrm{~min}$ (Figure 9). It was also observed that an exposure time of $15 \mathrm{~min}$ was significantly different to an exposure time of $1 \mathrm{~min}$ (Figure 9). Cluster analysis identified three clusters depending on the effect that 
chlorine effect had on biofouling (Cluster I $>$ II $>$ IIIA $>$ IIIB) and an ungrouped individual representing the control (Figure 10). Cluster I comprised long exposures (15 min) at the lowest and highest chlorine concentration. Cluster II comprised all chlorine concentrations when the exposure frequency was 0.5 min. Cluster III comprised two sub-clusters, IIIA and IIIB. Cluster IIIA comprised all chlorine concentrations, with exposure frequencies of 1 and 5 min except for low concentration with an exposure time of $0.5 \mathrm{~min}$, which along with the longest exposure of medium chlorine concentration (1\%) formed the second sub-cluster (IIIB).

The change in the optical properties caused by fouling on the chlorine-treated and non-treated coupons when compared with non-exposed coupons $(100 \%)$, revealed that the transmission level of the former did not change significantly whereas the latter showed significant changes. The transmission measurements of the fouled coupons revealed a decrease in transmission (by $\sim 20 \%$ ) of control coupons whereas in chlorine-treated coupons, transmission decreased up to $<2 \%$ (Figure 11). Amongst the chlorine-treated fouled coupons, transmission was found to be similar ( $>98 \%)$ irrespective of chlorine concentration and exposure time (Figure 9). This small loss of transmission could be due to negligible fouling.

\section{Discussion}

For the past few decades, chlorine has been used as the disinfectant of choice for water treatment due to its cost-effectiveness. The broad-spectrum biocidal activity of chlorine is mediated by hypochlorous acid, which is formed in aqueous solutions at pH 5-8 (Gardner and Peel 1991). The toxicity of chlorine is a function of several factors including concentration, $\mathrm{pH}$, exposure time and the type and quantity of chlorine compounds formed. Chlorination has been shown to eliminate aquatic organisms, but the concentration as well as exposure time required varies considerably with different organisms eg bacteria, algae c, zooplankton etc (see review by Gregg et al. 2009 and the references therein). Vegetative algal cells, free living bacteria and zooplankton can be killed at concentration ranging from 1-100 ppm chlorine and $5 \mathrm{~min}-72 \mathrm{~h}$ exposure, whereas dinocysts, zooplankton resting stages and Bacillus spores require considerably higher concentrations $(500-2500 \mathrm{ppm})$ and long exposure times (24h). It has also been reported that attached organisms require even higher doses compared to free living organisms suggesting that high amounts of organic matter eg EPS, interferes with the biocidal efficacy of chlorine. In case of Vibrio cholera, free living forms required $100 \mathrm{ppm}$ to kill the cells whereas cells attached to 
crab surfaces required $>800 \mathrm{ppm}$. Moreover the focus of the above studies (low concentrations and longer exposure time) was mainly targeted at killing the organisms whereas in the present investigation the focus of the study (higher concentration and shorter exposure) is not only to kill the organism, but also to remove the dead organisms from the surfaces. Thus, higher chlorine concentrations ie $0.5 \%, 1 \%$ and $2 \%(\mathrm{w} / \mathrm{v})$, and shorter exposure times $(0.5,1,5$ and $15 \mathrm{~min})$ were selected to evaluate the antifouling efficacy. Two of the advantages of a shorter exposure time is that the deterioration of materials on exposure to chlorine is minimised and that short pulses of chlorine may prove to be useful in preventing biofilm formation on the sensor heads of the oceanographic instruments, which are deployed in the marine environment for periods of weeks to months in order to capture scientific data.

\section{Effect of chlorine on fouling diatoms}

The experiments to evaluate the effect of chlorine on already developed biofilms revealed that all treatments were effective in removing the cells from both mono-species and multi-species biofilms when compared with control coupons. Furthermore, chlorine treatment of pre-existing biofilms showed it was effective in reducing the population of microalgae. This indicates that chlorine can 'clean' biofouling from a fouled surface.

Adhesion of pennate diatoms to surfaces is invariably associated with secretion of exopolysaccharides (EPS) from the raphe slit(s) (Chamberlain 1976; Hoagland et al. 1993; Cooksey and Cooksey 1995). Diatom adhesion is governed by a 2-stage process: reversible ('initial contact' or 'first kiss') followed by irreversible adhesion (permanent adhesion; see reviews by Wetherbee et al. 1998; Molino and Wetherbee 2008), both being facilitated by the production of EPS (Cooksey and Cooksey 1995). EPS also protects biofilms from adverse external conditions, and suggests that the removal of EPS from the cells in a biofilm will enhance the removal of diatom cells from the surface. In the work reported here, chlorine was effective against cells in biofilms. A study of Legionella pneumophila, a water borne pathogen in drinking water, revealed no visible EPS associated with cells in biofilms exposed to chlorination (Gião et al 2010). In order to confirm whether chlorine was also effective in removing EPS of cells in a diatom biofilm, alcian blue staining was carried out. The observations indicated that irrespective of concentration and exposure time chlorine treatment was efficient in removing EPS from cells directly associated with the cell surface. However it is unclear as to what effect (if any) the treatment has on EPS previously deposited (during adhesion process) on the 
substratum surface. Since chlorine is an efficient oxidizer of organic matter (Galindo-Lopez et al. 2009) and since no alcian blue staining was observed near the vicinity of the cells in the chlorine treated biofilms (Figures 2 and 3 ) it is possible that the chlorine treatments might have also removed a significant amount of EPS from the surface of the glass.

Chlorine was also effective in damaging chlorophyll. Similar results were also observed for Cocconeis scutellum, another dominant biofouling diatom (Nancharaiah et al. 2007). Further evidence for the degraded nature of the biofilm was the low values of the variable fluorescence $\left(F_{\mathrm{v}}\right)$, the ratio of variable and maximum $\left(F_{\mathrm{v}} / F_{\mathrm{m}}\right)$ fluorescence and high values of $\sigma_{\text {PSII. }} F_{\mathrm{v}}$ measurements showed a significant decrease in fluorescence values in chlorine-treated compared to control biofilms. The decrease in $F_{v}$ was due to the presence of degraded chlorophyll (Figure 5). $F_{\mathrm{v}} / F_{\mathrm{m}}$ is a measure of photosynthetic quantum efficiency (Kolber et al. 1988; 1990) and is known to range from 0.2 to 0.65 . If the $F_{\mathrm{v}} / F_{\mathrm{m}}$ is reduced, it indicates that a fraction of the PSII reaction center is functionally damaged/photoinhibited (Green et al. 1992; Kraus et al 1991) or the presence of more dead/dying cells (Franklin 2009; Perkins et al. 2010). The low $F_{\mathrm{v}} / F_{\mathrm{m}}$ values observed in chlorine-treated biofilms indicated that chlorination was efficient in killing the cells by damaging the PSII reaction centers. The functional absorption cross-section of PSII ( $\left.\sigma_{\text {PSII }}\right)$, which is derived from the rate of increase in between $F_{0}$ and $F_{m}$, describes the efficiency of light utilization for photochemistry in PSII. It is the product of the light-harvesting capability of the light-harvesting pigments and the efficiency of excitation transfer to the reaction center (Ley and Mauzerall 1982; Mauzerall and Green-Baum 1989; Dubinsky 1992). Any variation in the rate of increase between $F_{0}$ and $F_{m}$ will affect $\sigma_{\text {PSII }}$ values. The $\sigma_{\text {PSII values of the }}$ normal cells (control) of both Navicula and Amphora lie in the range of 300 to 400, but when they were treated with chlorine the values increased. The increase in $\sigma_{\mathrm{PSII}}$ values was due to the early saturation of the damaged chlorophyll and PSII reaction centers. A recent study reported that chlorine not only caused a reduction in growth and chlorophyll, but also primary productivity (Vinitha et al. 2010). Such an effect of chlorine on productivity could be due to damage to chlorophyll and photosystem II reaction centers. SEM images also indicated the algicidal effect of chlorine on diatoms cells.

In order to evaluate the growth of chlorine-treated diatom cells, coupons were incubated for a period of 5 days. No growth was observed in case of Amphora and Navicula biofilms, but a population increase was observed in natural biofilms. The increase due to the growth of particular diatom such as Amphiprora sp., Navicula spp., Cylindrotheca closterium and Coscinodiscus sp. Amongst these species, 
Amphiphrora sp. and Navicula spp. increased in abundance 3-fold, whereas Cylindrotheca closterium and Coscinodiscus sp showed a 2- and 1-fold increase, respectively (Table 2). Pleurosigma, Amphora and Thalassionema showed no increase in abundance after chlorine treatment. These observations indicate that biocidal effect of chlorine was species specific. A recent study by Vinitha et al. (2010) also indicated species-specific differences in tolerance and recovery among the diatoms tested (Vinitha et al. 2010).

\section{Influence of algal seeding on the development of chlorine treated biofilms}

Colonization of diatoms on clean surfaces immersed in the marine environment is well known. In a study in temperate and tropical Australia, bacteria and diatoms can also colonise antifouling paints containing biocides as well as non-biocidal fouling release surfaces (Molino et al. 2009a and b). It was hypothesized that fouling diatoms may be characterized by their ability to adhere and grow on surfaces already modified by bacterial biofilms. Organic booster biocides eg diuron and tolylfluanid, which are widely used in antifouling paints are more active against diatoms than bacteria (Fay et al. 2010). However similar information on the activity of chlorine against surfaces colonized by diatom biofilms is lacking. The present investigation showed that diatoms can also colonize, grow and actively photosynthesize on surfaces, which have been treated with chlorine. In the marine environment, the development of biofouling is a continuous process and cleaning a surface with an anifouling agent such as chlorine does not guarantee that the surface would remain clean. In order to keep the surface cleaner for longer necessitates a cleaning process at frequent intervals, for example by pulse chlorination.

\section{Effect of pulse chlorination on the development of natural biofilms}

It has been reported that the excess usage of chlorine, especially to treat large volumes such as a ship's ballast water will generate significant concerns due to the creation of persistent carcinogenic, organochloride by-products (see review by Gregg et al 2009). Hence it is essential to adopt a technique such as pulse-chlorination ${ }^{\circledR}$, a dosing technique developed by KEMA in 1998, that allows optimal antifouling

performance with amounts of chlorine(http://www.environmentalexpert.com/stse_resulteach_product.aspx?cid=2324\&idproduct=183 16\&codi=18316). 
Pulse-chlorination is based on the principle that, in general, mussels and clams have a recovery period before they open and start filtering after exposure to chlorination. The method takes advantage of this recovery time by using short successive periods of chlorination, alternating with periods without chlorine. This chlorination technique is nowadays the Best Available Technique (BAT) under the European Union terms of Integrated Pollution Prevention and Control (IPPC) for macro-fouling mitigation in marine and freshwater systems. However, the concept of pulse chlorination has not been investigated in detail for preventing the development of biofilms. In this study, an attempt was made to evaluate the effect of pulse chlorination ie chlorine treatment at $6 \mathrm{~h}$ intervals, in preventing biofilm development.

The results of the pulse chlorination experiment indicated that the chlorine treatments were effective in controlling the biofouling development when compared with the non-chlorine treatment. The results also revealed that among the chlorine treatments irrespective of the concentration, exposure time was important for controlling biofouling development. The prevention of biofouling at all concentrations and the increase in biofouling with a decrease in exposure time suggests that fouling occurred during the intervals between the $6 \mathrm{~h}$ cycles of exposure. It has been reported that the adhesion of fouling organisms such as bacteria, diatoms, invertebrate larvae and spores following initial contact takes place within a short period (Davies \& Geesy 1995; Lind et al. 1997; Higgins et al. 2003; Callow and Callow 2002). The strong inhibitive effect of chlorine on diatoms and their ability to colonize the chlorine-treated surfaces suggests that the increase in biofouling buildup during the 6 hour cycle was due to new recruitment/fresh colonization.

The results suggest that pulsed chlorination could be used to control biofouling development on optical windows of marine instruments deployed for long term recording of data. The threshold levels of fouling for optical instruments as well as the biofouling potential of the region would also need to be established. Considering the negligible reduction in optical transmission at the lowest chlorine concentration and exposure time as well as the efficacy against the already developed biofilms, the most appropriate chlorine concentration $(<0.5 \%)$, exposure time $(<0.5 \mathrm{~min})$ and the interval between the exposures $(>6 \mathrm{~h})$ needs to be examined. Since the amount of chlorine to keep an optical sensor head free from fouling is small, compared to the volumn of a ship's ballast water tank, it is that the potential for environmental damage will be negligible. This aspect and the potential of corrosion of materials caused by chlorine treatment needs to be examined. 


\section{Acknowledgements}

We are grateful to Director, National Institute of Oceanography, CSIR (Goa, India) and Dr. AC Anil for their support and encouragement. We thank Mr. Khedekar for his help with scanning electron microscopy (SEM). They also thank the editor and three anonymous reviewers for their suggestions in improving the manuscript. This paper is a NIO contribution....

\section{References}

Alliance for Coastal Technologies (ACT) 2003. Biofouling Prevention Technologies for Coastal Sensors/Sensor Platforms Solomons, Maryland, Nov. 2003, ACT No. 03-05/UMCES Technical Report Series TS-426-04-CML, http://www.actonline.ws/Technologies.html

Bak J, Ladefoged SD, Begovic T, Winding A. 2010a. UVC fluencies for preventative treatment of Pseudomonas aeruginosa contaminated polymer tubes. Biofouling 26:821-828.

Bak J, Ladefoged SD, Tvede M, Begovic T, Gregersen A. 2010b. Disinfection of Pseudomonas aeruginosa biofilm contaminated tube lumens with ultraviolet $\mathrm{C}$ light emitting diodes. Biofouling 26:31-38.

Bakker DP, Klijnstra JW, Busscher HJ, van der Mei H. 2003. The effect of dissolved organic carbon on bacterial adhesion to conditioning films adsorbed on glass from natural seawater collected during different seasons. Biofouling 19:391 - 397.

Bhosle NB, Garg A, Fernandes L, Citon P. 2005. Dynamics of amino acids in the conditioning film developed on glass panels immersed in the surface seawaters of Dona Paula Bay. Biofouling 21:99- 107.

Callow ME, Callow JA. 2002. Marine biofouling: a sticky problem. Biologist 49:1-5

Chamberlian AHL. 1976. Algal settlement and secretion of adhesive material. In: Sharpley JM, Kaplan AM (eds.) Proc 3rd Int Biodegradation Symp. Applied Science, London, 417-432

Cooksey KE, Wigglesworth-Cooksey B. 1995. Adhesion of bacteria and diatoms to surfaces in the sea: a review. Aq Microbial Ecol 9: 87-96

Davies DG, Geesey GG. 1995. Regulation of the alginate biosynthesis gene algC in Pseudomonas aeruginosa during biofilm development in continuous culture. Appl Environ Microbiol 61: 860867

Dobretsov S, Dahms H-U, Qian P-Y (2006) Inhibition of biofouling by marine microorganisms and their metabolites. Biofouling 22: 43-54

Dobretsov S, Teplitski M, Paul V. 2009. Mini-review: Quorum sensing in the marine environment and its relationship to biofouling. Biofouling 25: 413-427. 
Dubinsky Z. 1992. The optical and functional cross-sections of phytoplankton photosynthesis. In: Falkowskii, P.G., and Woodhead, A.D., (Eds) Primary productivity and biogeochemical cycles in the sea. Plenum, New York, p31-45

Faÿ F, Linossier I, Carteau D, Dheilly A, Silkina A, Vallée-Réhel K. 2010. Booster biocides and microfouling. Biofouling 26 (7): $787-798$

Franklin D, Choi C, Hughes C, Malin G, Berges J. 2009. Effect of dead phytoplankton cells on the apparent efficiency of photosystem II. Mar Ecol Prog Ser 382: 35-40

Gardner JF, Peel MM. 1991. Introduction to sterilisation, disinfection and infection control. Churchill Livingstone, United Kingdom Gavand, MR, McClintock

Gião MS, Wilks S, Azevedo NF, Vieira MJ, Keevil CW. 2009. Incorporation of natural uncultivable Legionella pneumophila into potable water biofilms provides a protective niche against chlorination stress. Biofouling 25 (4): $345-351$

Greene RM, Geider RJ, Falkowskii PG. 1992. Effect of iron limitation on photosynthesis on a marine diatom. Limnol and Oceanogr 36: 1772-1782

Gregg M, Rigby G, Hallegraeff GM. 2009. Review of two decades of progress in the development of management options for reducing or eradicating phytoplankton, zooplankton and bacteria in ship's ballast water. Aquatic Invasions 4(3): 521-565

Guillard RRL, Ryther JH. 1962. Studies of marine planktonic diatoms. I. Cyclotella nana Hustedt, and Detonula confervaceae (Cleve Gran). Can J Microbiol 8: 229-239.

Hoagland KD, Rosowski JR, Gretz MR, Roemer SC. 1993. Diatom extracellular polymeric substances: function, fine structure,chemistry and physiology. J Phycol 29: 537-566.

Higgins MJ, Molino P, Mulvaney P, Wetherbee R. 2003. The structure and nanomechanical properties of the adhesive mucilage that mediates diatom-substratum adhesion and motility. J Phycol 39: $1181-1193$

Jain, Anand and Bhosle, Narayan B.(2009) 'Biochemical composition of the marine conditioning film: implications for bacterial adhesion. Biofouling 25 (1): $13-19$

Kolber Z, Zehr J, Falkowskii PG. 1988. Effects of growth irradiance and nitrogen limitation on photosynthetic energy conversion in photosystem II. Plant Physiol;88: 923-929

Kolber Z, Wyman KD, Falkowskii PG. 1990. Natural variability in photosynthetic energy conversion efficiency: a study in the Gulf of Maine. Limnol Oceanogr 35: 72-9

Loeb GI, Neihof RA. 1975. Marine conditioning films. Adv Chem 145:319 - 335.

Kraus GH, Weis E. 1991. Chlorophyll fluorescence and photosynthesis: The basics. Ann Rev Plant Physiol and Plant Mol Biol 42: 13-349 
Lakretz, Anat, Ron, Eliora Z. andMamane, Hadas(2010) 'Biofouling control in water by various UVC wavelengths and doses', Biofouling, 26: 3, $257-267$,

Ley AC, Mauzerall D. 1982. Absolute absorption cross-sections for photosystem II and the minimum quantum requirement for photosynthesis on Chlorella vulgaris. Biochim Biophy Acta 680: 95106

Lind JL, Heimann K, Miller EA, van Vliet C, Hoogenraad NJ, Wetherbee R. 1997. Substratum adhesion and gliding in diatoms are mediated by extracellular proteoglycans. Planta 203:213-221

López-Galindo C. Casanueva JF. Nebot E. 2010. Efficacy of different antifouling treatments for seawater cooling systems. Biofouling 26 (8): 923-930

Mauzerall D, Green-Baum NL. 1989. The absolute size of a photosynthetic unit. Biochim et Biophy Acta 974: 119-140

Molino P J, Wetherbee R. 2008. Mini-review: The biology of biofouling diatoms and their role in the development of microbial slimes. Biofouling 24: 365-379.

Molino PJ, Samantha C, Eason H, Maeve R, Carey JM, Burgman MA, Wetherbee R. 2009. Development of the primary bacterial microfouling layer on antifouling and fouling release coatings in temperate and tropical environments in Eastern Australia. Biofouling 25 (2): 149 162

Molino PJ, Campbell E, Wetherbee R. 2009. Development of the initial diatom microfouling layer on antifouling and fouling-release surfaces in temperate and tropical Australia. Biofouling 25 (8): $685-694$

Nancharaiah YV, Rajadurai M, Venugopalan VP. 2007 Single cell level microalgal ecotoxicity assessment by confocal microscopy and digital image analysis. Env Sci Tech 41: 2617-2621

Patil JS, Anil AC. 2005a. Biofilm diatom community structure: Influence of temporal and substratum variability. Biofouling 21(3/4):189-206

Patil JS, Anil AC. 2005b. Quantification of diatoms in biofilm: standardization of methods. Biofouling 21(3/4): 181-188

Patil JS, Kimoto H, Kimoto T, Saino T. 2007. Ultraviolet radiation (UV-C): a potential tool for the control of biofouling on marine optical instruments. Biofouling 23(4): 215-230

Perkins KJ, Andrewartha JM, McMinn A, Cook SS, Hallegraeff GM. 2010. Succession and physiological health of freshwater microalgal fouling in a Tasmanian hydropower canal. Biofouling 26 (6): 637 - 644

Phe MH, Dossot M, Block JC. 2004. Chlorination effect on the fluorescence of nucleic acid staining dyes. Water Res 38: 3729-3737. 
Phe MH, Dossot M, Guilloteau H, Block JC. 2005. Nucleic acid fluorochromes and flow cytometry prove useful in assessing the effect of chlorination on drinking water bacteria. Water Res 39: 3618-3628.

Poornima EH, Rajadurai M, Rao TS, Anupkumar B, Rajamohan R, Narasimhan SV, Rao VNR,. Venugopalan VP. Impact of thermal discharge from a tropical coastal power plant on phytoplankton. J Thermal Biol 30:307-316.

Railkin AI. 2004. Marine Biofouling: Colonization Processes and Defenses, CRC Press, Boca Raton, Fl, USA. pp 303

Saby S, Sibille I, Mathieu L, Paquin JL, Block JC. 1997. Influence of water chlorination on the counting of bacteria with DAPI (4£,6-diamidino-2-phenylindole). App Environ Microbiol 63: 1564-1569.

Schultz MP, Bendick JA, Holm ER, Hertel WM. 2011. Economic impact of biofouling on a naval surface ship. Biofouling 27: 87-98.

Vinitha E, Veeramani P, Venugopalan VP. 2010. Chlorination for power plant biofouling control: potential impact on entrained phytoplankton. Int J Environ Studies 67(4): 515 - 530

Wetherbee R, Lind JL, Burke J. 1998. The first kiss: Establishment and control of initial adhesion by raphid diatoms. J Phycol 34: 9-15 
Table 1. Effect of chlorine concentration and exposure time on the abundance of cells in mono-species (Amphora and Navicula) biofilms.

\begin{tabular}{|c|c|c|c|c|c|c|c|c|c|c|c|c|c|}
\hline \multirow{2}{*}{\multicolumn{2}{|c|}{ Treatments }} & \multicolumn{4}{|c|}{ Amphora } & \multicolumn{4}{|c|}{ Navicula } & \multicolumn{4}{|c|}{ Natural } \\
\hline & & \multicolumn{2}{|c|}{ Day 0} & \multicolumn{2}{|c|}{ Day 5} & \multicolumn{2}{|c|}{ Day 0} & \multicolumn{2}{|c|}{ Day 5} & \multicolumn{2}{|c|}{ Day 0} & \multicolumn{2}{|c|}{ Day 5} \\
\hline Concentration & Exposure & Total & Live & Total & Live & Total & Live & Total & Live & Total & Live & Total & Live \\
\hline Control & & $597 \pm 61$ & $597+61$ & $1376+486$ & $1376+486$ & $564+181$ & $564+181$ & $817 \pm 153$ & $817+153$ & $97+21$ & $97+21$ & $641+514$ & $641+514$ \\
\hline \multirow[t]{2}{*}{$0.50 \%$} & $1 \mathrm{~min}$ & $272+54$ & 0 & 0 & 0 & $221 \pm 63$ & $10 \pm 6$ & $221+32$ & $1 \pm 0$ & $55+29$ & $12+7$ & $128+72$ & $37 \pm 27$ \\
\hline & $5 \mathrm{~min}$ & $201+128$ & 0 & 0 & 0 & $244+63$ & $13 \pm 0$ & $248 \pm 70$ & $0 \pm 0$ & $58+51$ & $41+3$ & $102+21$ & $5 \pm 18$ \\
\hline \multirow[t]{2}{*}{$1 \%$} & $1 \mathrm{~min}$ & $194+22$ & 0 & 0 & 0 & $125 \pm 84$ & $5 \pm 1$ & $84 \pm 2$ & $1 \pm 0$ & $29+9$ & $4 \pm 2$ & $61 \pm 45$ & $33 \pm 5$ \\
\hline & $5 \mathrm{~min}$ & $149+17$ & 0 & 0 & 0 & $64 \pm 0$ & $2 \pm 1$ & $54 \pm 0$ & $2 \pm 0$ & $31+1$ & $13 \pm 1$ & $51 \pm 38$ & $19 \pm 15$ \\
\hline
\end{tabular}


Table 2. Results of 2-way ANOVA and Tukey's multiple comparison test ( $\alpha=0.05)$. Effect of chlorine concentrations and exposure times on diatoms and biofouling buildup in previously developed biofilms as well as on the growth of diatoms in chlorine-treated biofilms when incubated with and without cells. Efficiency of chlorine treatment was analyzed individually by Tukey's multiple comparison test $(\alpha=0.05)$. The treatments that are significantly different from controls and chlorine treatments $(0.5 \%$ chlorine exposure $1 \mathrm{~min}, 0.5 \%$ chlorine exposure $5 \mathrm{~min}, 1 \%$ chlorine exposure $1 \mathrm{~min}$ and $1 \%$ chlorine exposure for $5 \mathrm{~min}$ ) are represented by letters 'a', 'b', 'c' and 'd' respectively.

\begin{tabular}{|c|c|c|c|c|c|c|}
\hline \multirow{3}{*}{ Biofilms } & \multicolumn{2}{|c|}{ 2-way ANOVA } & \multicolumn{4}{|c|}{ Tukey's multiple comparison test } \\
\hline & \multirow{2}{*}{$\begin{array}{c}\text { Days } \\
p \text { value }\end{array}$} & \multirow{2}{*}{$\begin{array}{c}\text { Treatments } \\
\text { p value } \\
\end{array}$} & \multicolumn{2}{|c|}{$0.5 \%$ chlorine } & \multicolumn{2}{|c|}{$1 \%$ chlorine } \\
\hline & & & $\begin{array}{c}\text { 1min } \\
\text { exposure }\end{array}$ & $\begin{array}{c}5 \mathrm{~min} \\
\text { exposure }\end{array}$ & $\begin{array}{c}\text { 1min } \\
\text { exposure }\end{array}$ & $\begin{array}{c}5 \mathrm{~min} \\
\text { exposure }\end{array}$ \\
\hline a. Incubation without cells & & & & & & \\
\hline Amphora coffeaeformis & $<0.001$ & $<0.001$ & $\mathrm{a}$ & $\mathrm{a}$ & $\mathrm{a}$ & $\mathrm{a}$ \\
\hline Navicula transitans & $<0.001$ & 0.050 & $\mathrm{a}$ & a & ac & $a b c$ \\
\hline Natural & 0.014 & 0.001 & $\mathrm{a}$ & $\mathrm{a}$ & $\mathrm{a}$ & $\mathrm{a}$ \\
\hline b. Incubation with cells & & & & & & \\
\hline Amphora coffeaeformis & $<0.001$ & $<0.001$ & $\mathrm{a}$ & a & $a b$ & $a b$ \\
\hline Navicula transitans & $<0.001$ & $<0.001$ & $\mathrm{a}$ & $\mathrm{a}$ & $\mathrm{a}$ & abcd \\
\hline
\end{tabular}


Table 3. Effect of chlorine concentration and exposure time on the abundance of cells in multi-species (natural) biofilms.

\begin{tabular}{|c|c|c|c|c|c|c|c|c|c|c|}
\hline \multirow{4}{*}{ Species } & \multirow{3}{*}{\multicolumn{2}{|c|}{ Control }} & \multicolumn{8}{|c|}{ Chlorine treatments } \\
\hline & & & \multicolumn{4}{|c|}{$0.5 \%$ concentration } & \multicolumn{4}{|c|}{$1 \%$ concentration } \\
\hline & & & \multicolumn{2}{|c|}{1 min exposure } & \multicolumn{2}{|c|}{5 min exposure } & \multicolumn{2}{|c|}{1 min exposure } & \multicolumn{2}{|c|}{5 min exposure } \\
\hline & Day 0 & Day 5 & Day 0 & Day 5 & Day 0 & Day 5 & Day 0 & Day 5 & Day 0 & Day 5 \\
\hline Pleurosigma & 55 & 27 & 0 & 4 & 0 & 84 & 0 & 0 & 0 & 0 \\
\hline Amphiphora & 561 & 3484 & 156 & 591 & 27 & 2306 & 23 & 575 & 22 & 575 \\
\hline Thalassionema & 114 & 16 & 47 & 16 & 101 & 16 & 18 & 3 & 51 & 3 \\
\hline Amphora & 106 & 0 & 0 & 8 & 0 & 70 & 0 & 0 & 0 & 0 \\
\hline Navicula & 738 & 3132 & 119 & 425 & 160 & 1278 & 54 & 636 & 84 & 92 \\
\hline Cyllindrotheca & 1273 & 3851 & 426 & 707 & 527 & 504 & 437 & 679 & 234 & 72 \\
\hline Coscinodiscus & 60 & 7 & 0 & 23 & 0 & 28 & 0 & 4 & 0 & 12 \\
\hline Helicotheca tamensis & 1 & 0 & 0 & 0 & 0 & 4 & 0 & 0 & 0 & 0 \\
\hline Others & 396 & 416 & 359 & 1042 & 359 & 770 & 0 & 296 & 303 & 287 \\
\hline Total & 3303 & 10933 & 1107 & 2816 & 1174 & 5060 & 532 & 2193 & 694 & 1041 \\
\hline
\end{tabular}


Table 4. Effect of chlorine concentration and exposure time on concentration of chlorophyll $a(\mu \mathrm{g}$ coupon $^{-1}$ ) in mono-species (Amphora and Navicula) and multi-species (natural) biofilms.

\begin{tabular}{|c|c|c|c|c|}
\hline \multicolumn{2}{|c|}{ Chlorine treatment } & \multicolumn{3}{|c|}{ Chlorophyll (ug/coverslip) } \\
\hline Concentration & $\begin{array}{c}\text { Exposure time } \\
\text { (min) }\end{array}$ & A. coffeaeformis & N. transitans & Natural \\
\hline Control & & $53.80+8.71$ & $4.40+1.50$ & $7.07+4.61$ \\
\hline \multirow[t]{2}{*}{$0.50 \%$} & $1 \mathrm{~min}$ & $1.90 \pm 0.75$ & $0.36 \pm 0.11$ & $0.40 \pm 0.19$ \\
\hline & $5 \min$ & $0.37 \pm 0.00$ & $0.31 \pm 0.07$ & $0.25 \pm 0.14$ \\
\hline \multirow[t]{2}{*}{$1 \%$} & $1 \mathrm{~min}$ & $0.37 \pm 0.01$ & $0.29 \pm 0.03$ & $0.18 \pm 0.05$ \\
\hline & $5 \mathrm{~min}$ & $0.33+0.01$ & $0.19+0.02$ & $0.17+0.10$ \\
\hline
\end{tabular}


Table 5. Influence of algal seeding on chlorine-treated biofilms of Amphora and Navicula.

\begin{tabular}{|c|c|c|c|c|c|c|c|}
\hline \multicolumn{2}{|c|}{ Chlorine treatment } & \multicolumn{3}{|c|}{ Amphora coffeaeformis } & \multicolumn{3}{|c|}{ Navicula transitans } \\
\hline Concentration & Exposure time & Day 0 & Day 3 & Day 7 & Day 0 & Day 3 & Day 7 \\
\hline Control & & $3654 \pm 1183$ & $4021+1397$ & $4483+99$ & $1235+205$ & $2866+393$ & $4539 \pm 790$ \\
\hline \multirow[t]{2}{*}{$0.50 \%$} & $1 \mathrm{~min}$ & 0 & $630 \pm 415$ & $1631 \pm 415$ & 0 & $76 \pm 76$ & $471 \pm 14$ \\
\hline & $5 \mathrm{~min}$ & 0 & $359 \pm 205$ & $1775+205$ & 0 & $48+16$ & $476 \pm 53$ \\
\hline \multirow[t]{2}{*}{$1 \%$} & $1 \mathrm{~min}$ & 0 & $168 \pm 165$ & $635 \pm 165$ & 0 & $62 \pm 61$ & $494 \pm 81$ \\
\hline & $5 \mathrm{~min}$ & 0 & $297 \pm 312$ & $444 \pm 132$ & 0 & $159 \pm 13$ & $565+36$ \\
\hline
\end{tabular}




\section{Figure legends}

Figure 1. Effect of chlorine concentration and exposure time on the growth of mono-species (Amphora and Navicula) and multi-species (natural) biofilms. Abundance data are normalized to the control and are expressed as \%.

Figure 2. Micrographs of control and chlorine-treated biofilms of Amphora a. Alcian blue staining, $b$. Light microscope images, c. Epifluorescence images (red fluorescence in the control micrographs is due to the presence of chlorophyll; green fluorescence is a default resulted due to changes in contrast and brightness necessary to gain clear image of the chlorine treated cells); d. Scanning electron microscopy (SEM) images.

Figure 3. Micrographs of control and chlorine-treated biofilms of Navicula a. Alcian blue staining, b. Light microscope images, c. Epifluorescence images (red fluorescence in the control micrographs is due to the presence of chlorophyll; green fluorescence is a default resulted due to changes in contrast and brightness necessary to gain clear image of the chlorine treated cells); d. Scanning electron microscopy (SEM) images.

Figure 4. Effect of chlorine concentration and exposure time on concentration of chlorophyll ' $a$ ' in mono-species (Amphora and Navicula) and multi-species (natural) biofilms. The chlorophyll data are normalized to controls and expressed as percentages. Efficiency of chlorine treatments was individually analyzed by Tukey's multiple comparison test $(\alpha=0.05)$. In this figure, only the significant differences between the chlorine treatments and control are shown. The treatments that are significantly different from the control and chlorine treatments $(0.5 \%$ chlorine and 1 min exposure time) are represented by letters ' $a$ ' and ' $b$ ' respectively above the vertical bars.

Figure 5. Effect of chlorine concentration and exposure time on variable fluorescence $\left(F_{\mathrm{v}}\right)$, quantum yield $\left(F_{\mathrm{v}} / F_{\mathrm{m}}\right)$ and functional absorption cross-section $\left(\sigma_{\mathrm{PSII}}\right)$ in Amphora and Navicula biofilms. The $F_{\mathrm{v}}$ and $\sigma_{\mathrm{PSII}}$ data are normalized to the control.

Figure 6. Influence of algal seeding on chlorine-treated biofilms of Amphora and Navicula. Abundance data are normalized to the control.

Figure 7. Influence of algal seeding on variable fluorescence $\left(F_{\mathrm{v}}\right)$, quantum yield $\left(F_{\mathrm{v}} / F_{\mathrm{m}}\right)$ and functional absorption cross-section ( $\left.\sigma_{\mathrm{PSII}}\right)$ of chlorine-treated Amphora and Navicula biofilms.

Figure 8. Effect of chlorine concentration and exposure time in the control of biofouling development (buildup and chlorophyll $a$ ) over glass coupons exposed for a period of 15 days in a tank containing natural seawater. The data presented are normalized with respective controls. One-way ANOVA and Tukey's multiple comparison test $(\alpha=0.05)$ were conducted to evaluate efficiency of exposure time of chlorine at different concentrations. In this figure, only the significant differences between the chlorine treatments and control are shown. The exposure time of chlorine that is significantly different from control 
and exposure times $(0.5,1,5$ and $15 \mathrm{~min})$ are represented by letters ' $a$ ', 'b' 'c' and 'd' respectively above the vertical bars.

Figure 9. Effect of chlorine concentration ( $\mathrm{a} \& \mathrm{~b}$ ) and exposure time on (a' \& b') biofilm chlorophyll $a$ (a \& a') and biofouling buildup (b \& b') over glass coupons after 15 days of immersion in a tank containing natural sea water. The normalized data obtained for different chlorine exposure time for each exposure period as well as for chlorine exposure time for each concentration were pooled. One-way ANOVA and Tukey's multiple comparison test $(\alpha=0.05)$ was conducted to individually evaluate the efficiency of exposure time and concentration of chlorine. In the figures, only the significant differences between the chlorine treatments and control are shown. In figures (a) and (b) the chlorine concentrations that are significantly different from control are represented by the letter ' $a$ ' above vertical bars. Whereas in figures (c) and (d) the exposure time of chlorine that is significantly different from the control and exposure times $(0.5,1,5$ and $15 \mathrm{~min})$ are represented by letters ' $a$ ', ' $b$ ' and 'c' respectively above the vertical bars.

Figure 10. Cluster dendrogram of the effect of chlorine concentration and exposure time on biofouling using the Bray-Curtis similarity coefficient and the group average method. The chlorine concentrations $2 \%, 1 \%$ and $0.5 \%$ are indicated by letters ' $\mathrm{H}$ ', ' $\mathrm{M}$ ' and ' $\mathrm{L}$ ' respectively.

Figure 11. Effect of concentration and exposure time of chlorine on the optical transmission of fouled glass coupons obtained after 15 days of immersion in a tank containing seawater. 

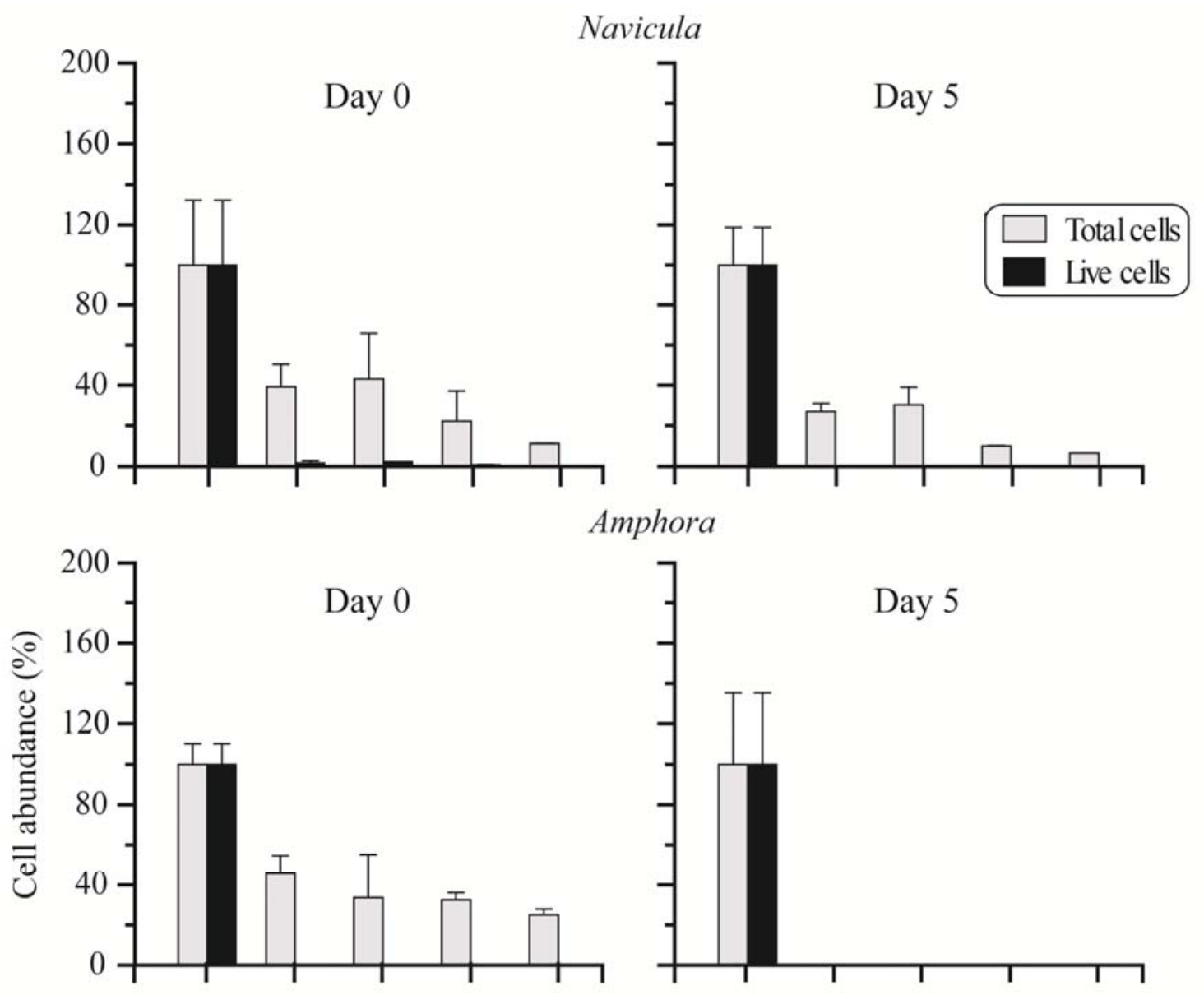

Natural sea water.
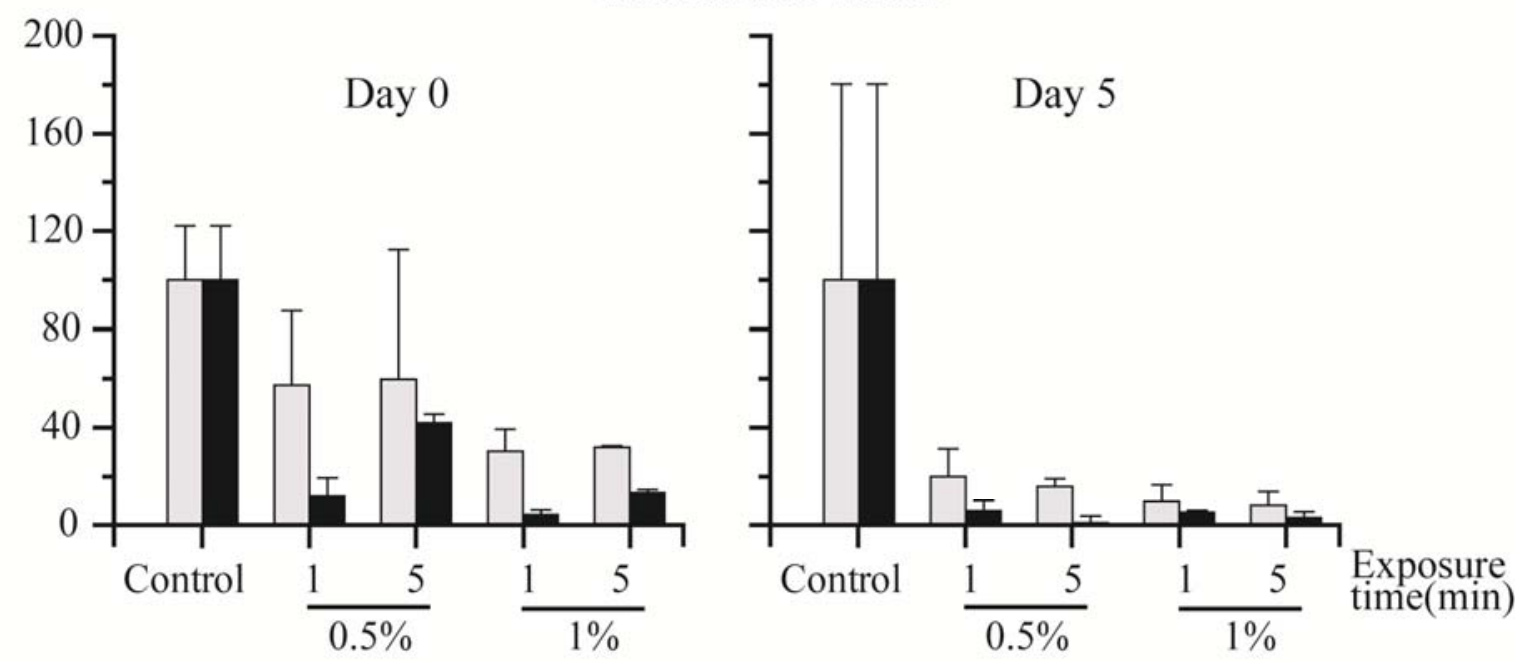

Chlorine concentrations (\%)

Figure 1 


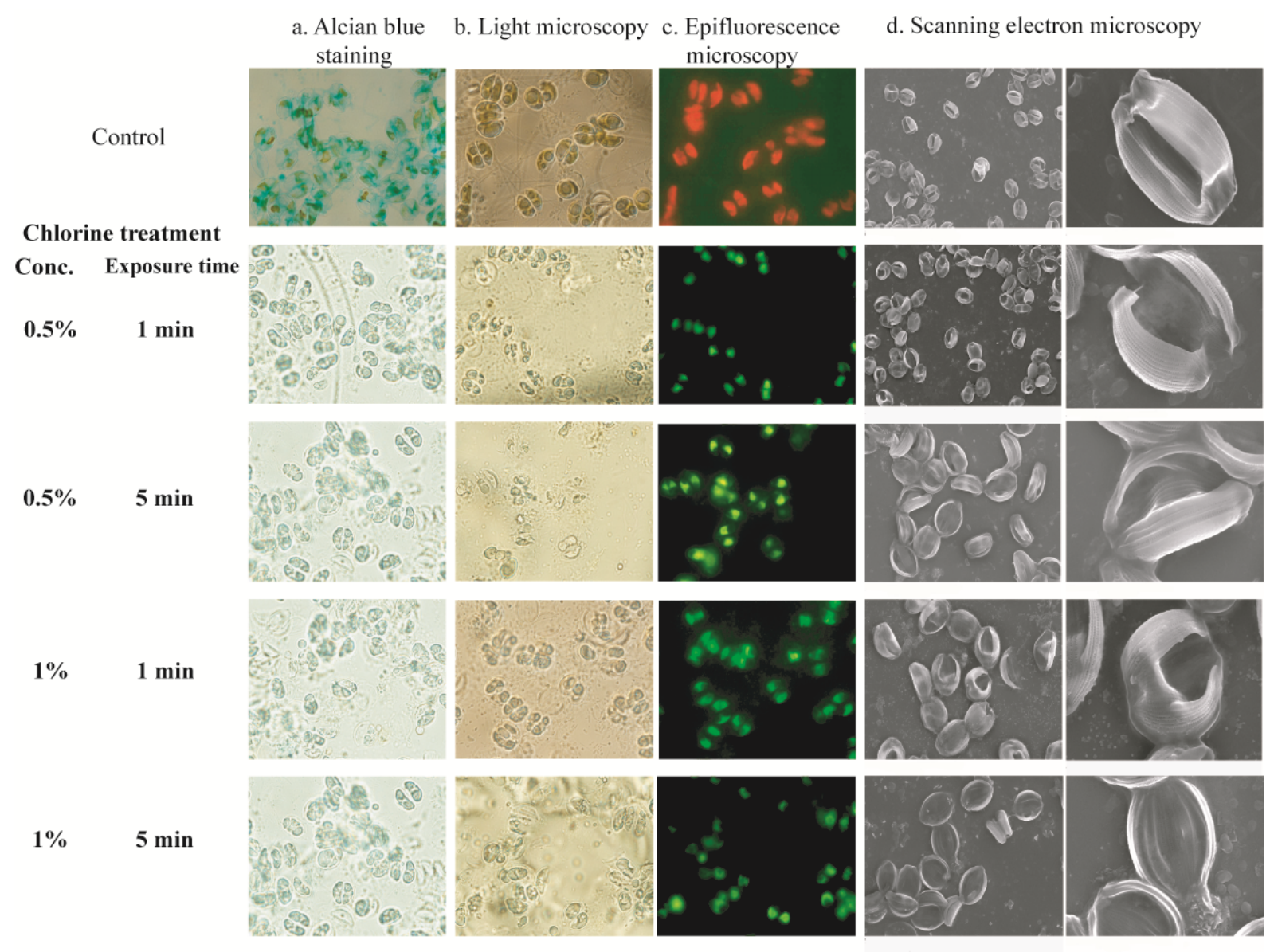

Figure 2 


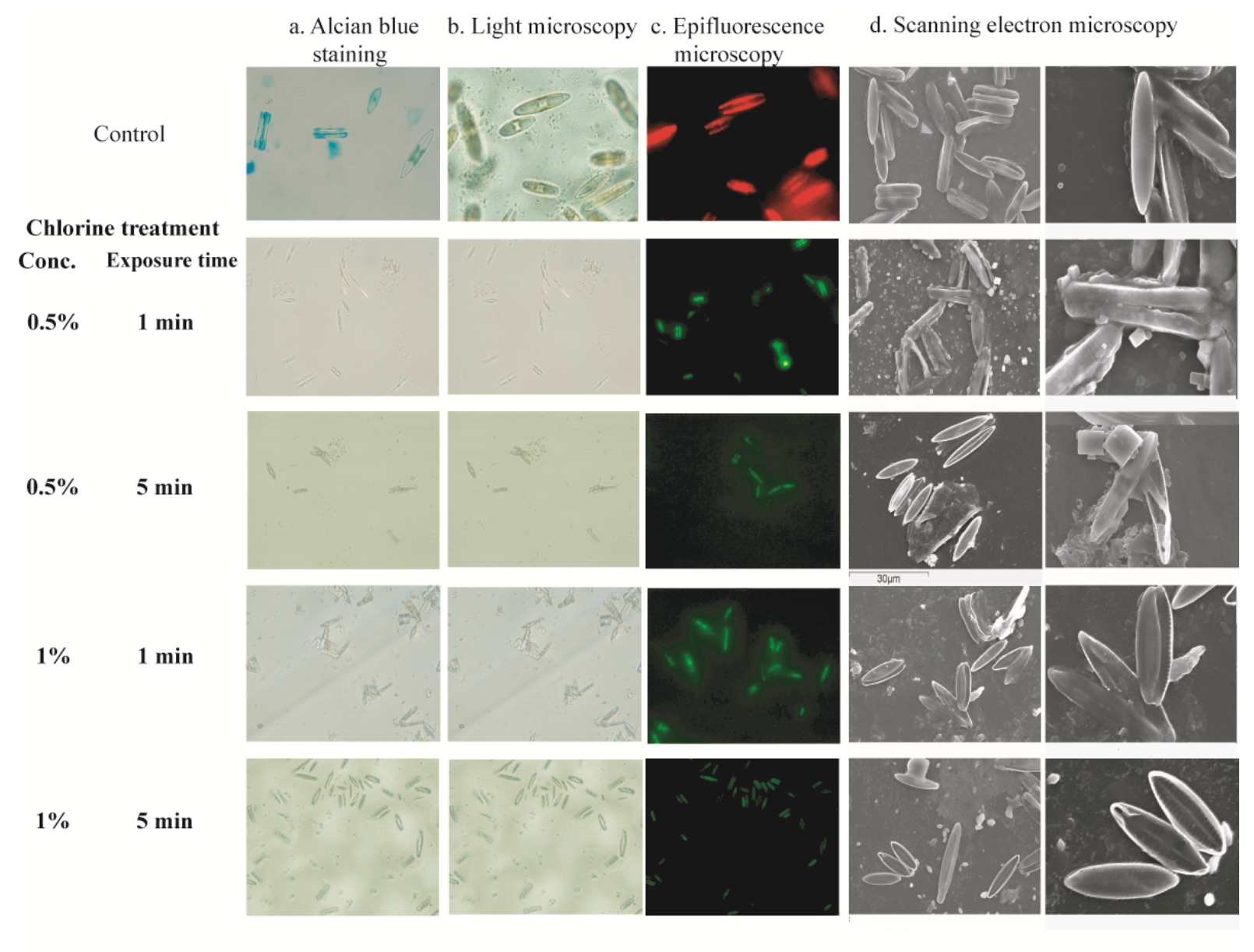

Figure 3 


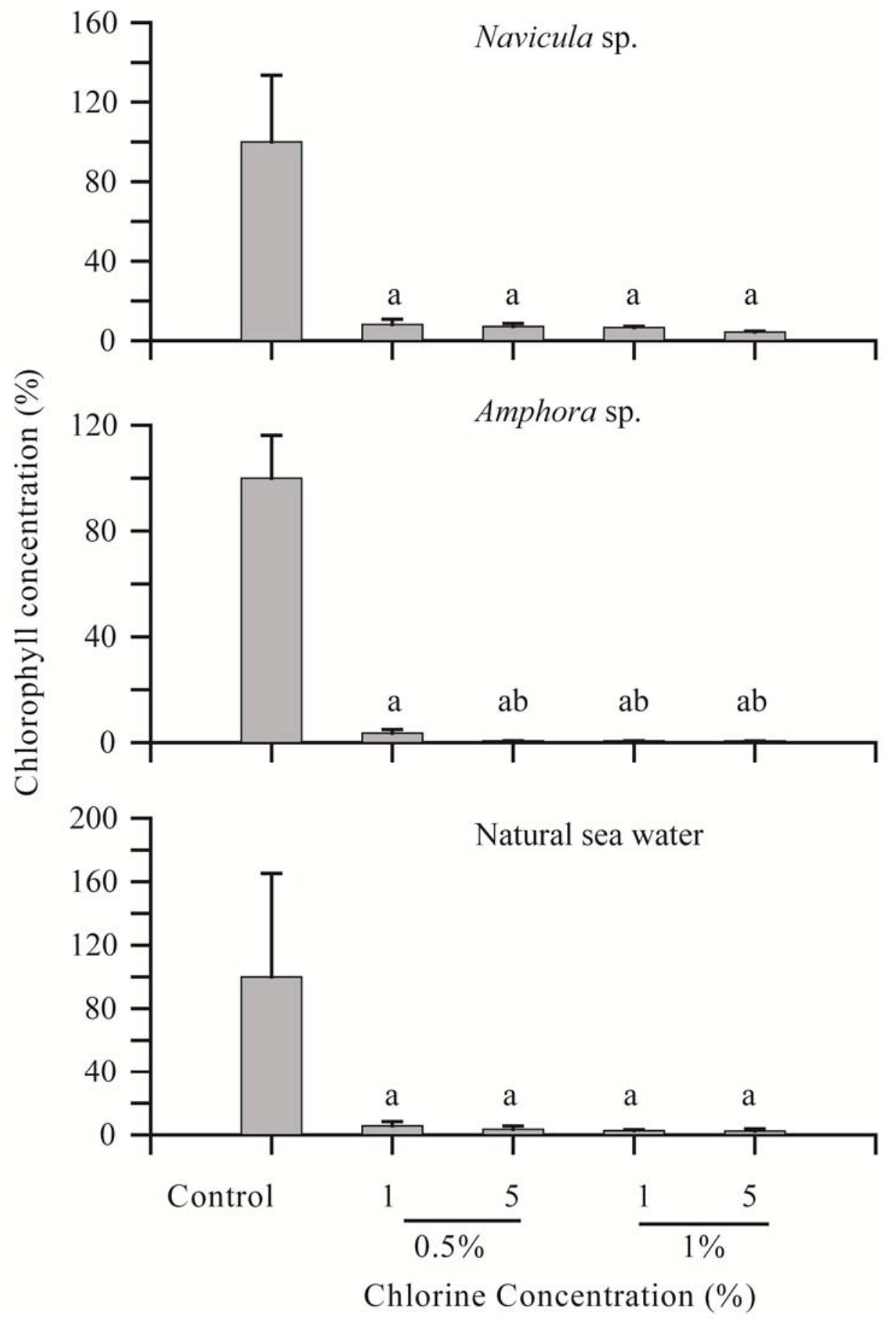

Figure 4 

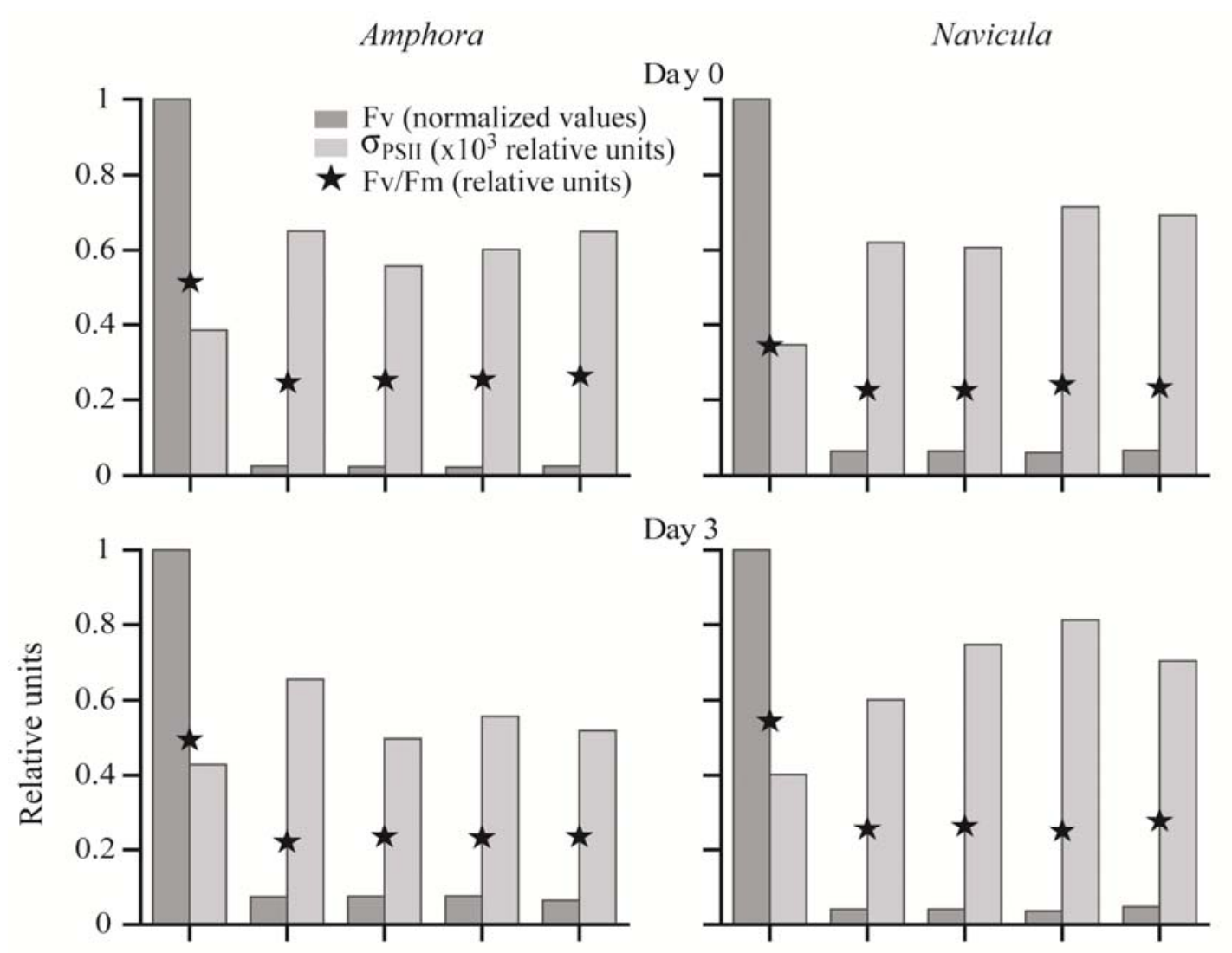

Day 3

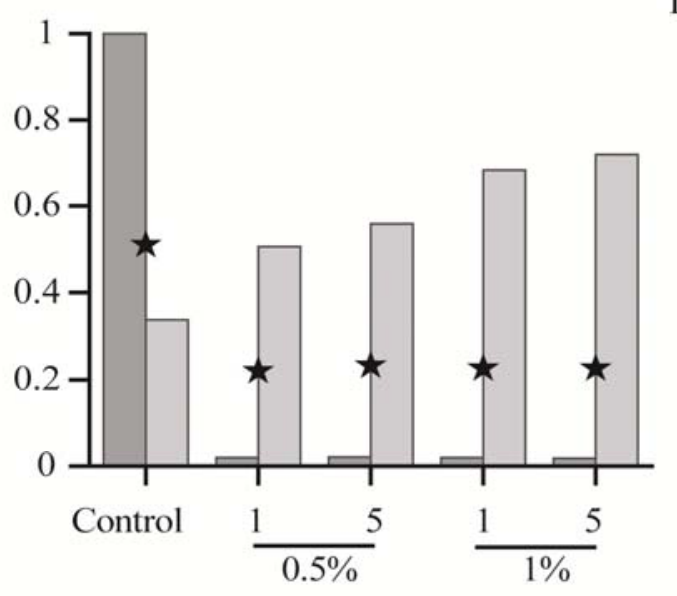

Day 7
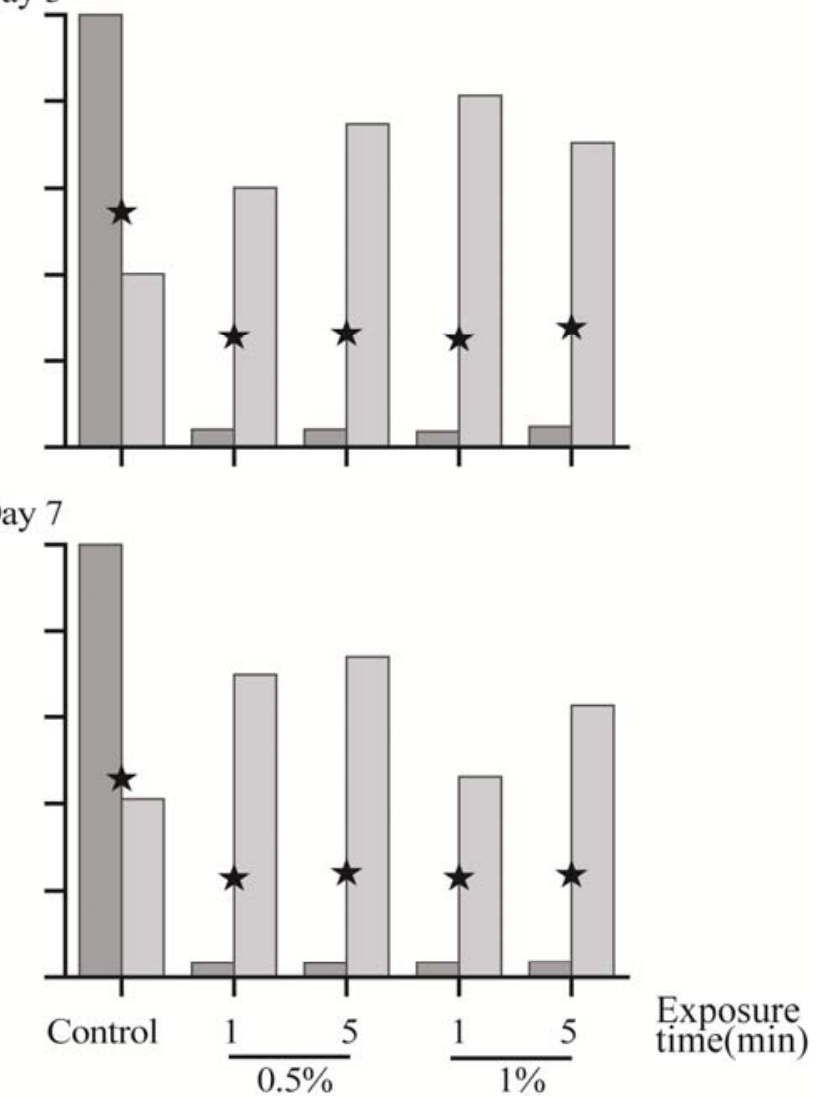

Chlorine concentrations (\%)

Figure 5 

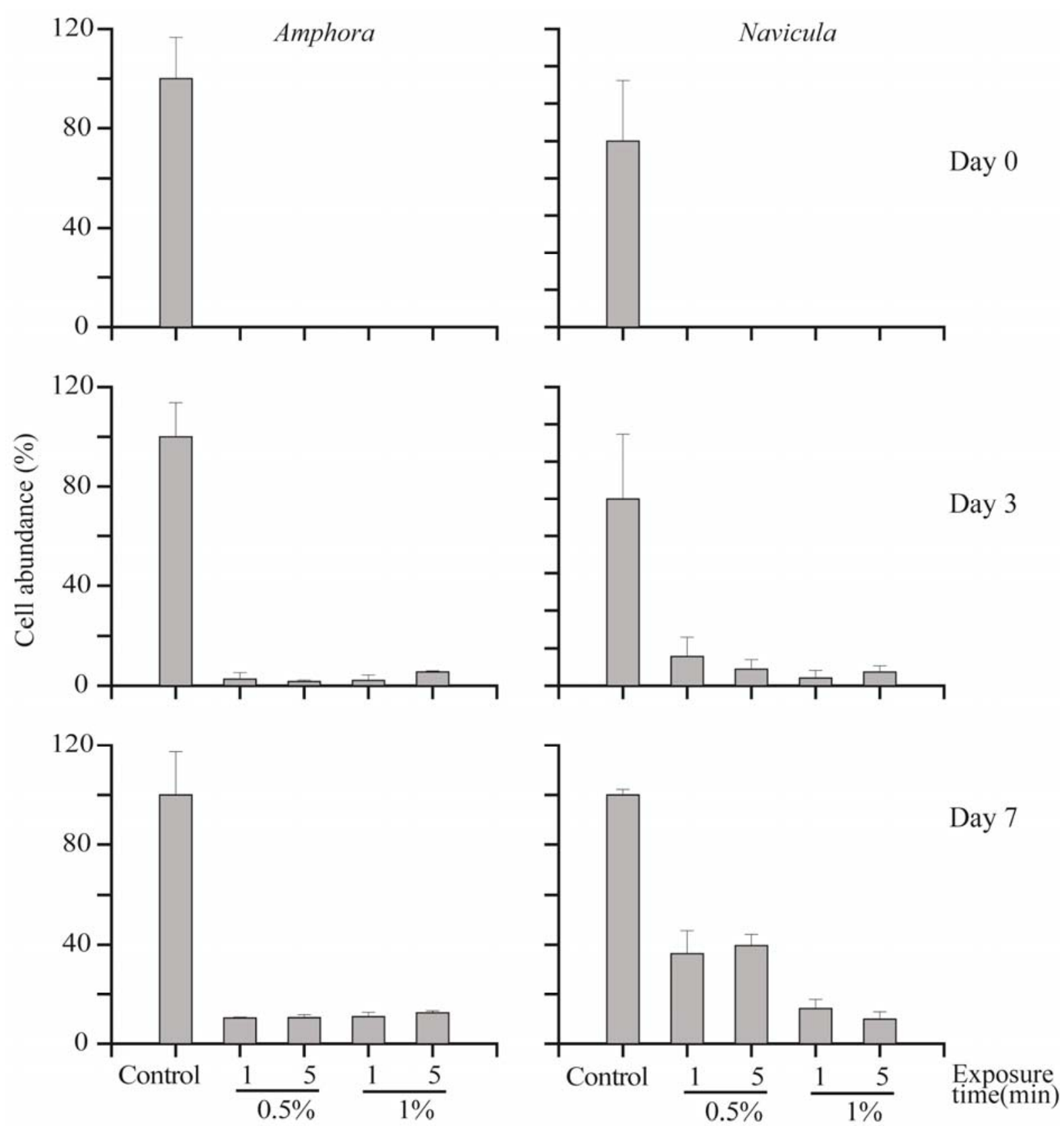

Chlorine concentrations (\%)

Figure 6 

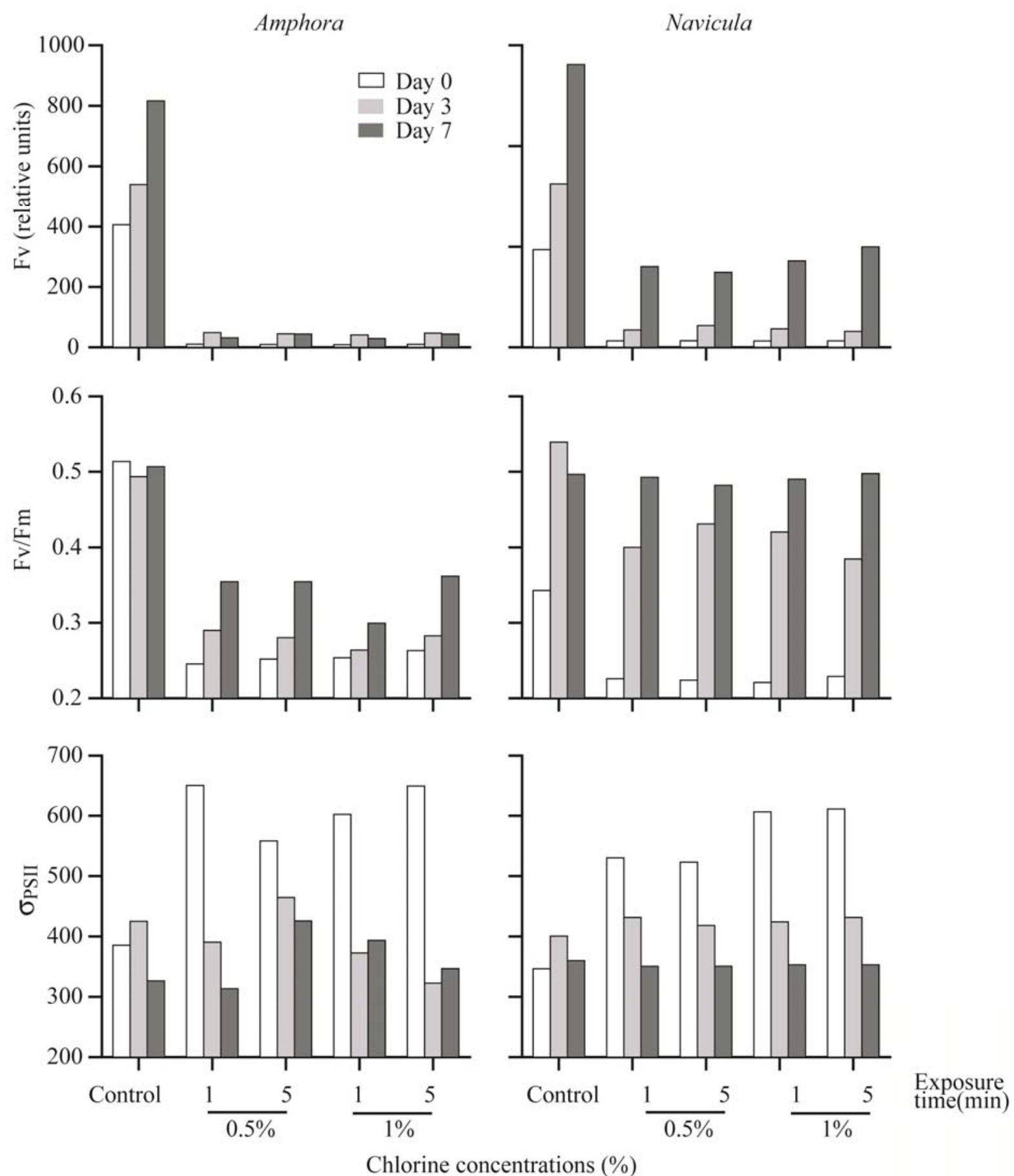

Figure 7 
Biofouling buildup
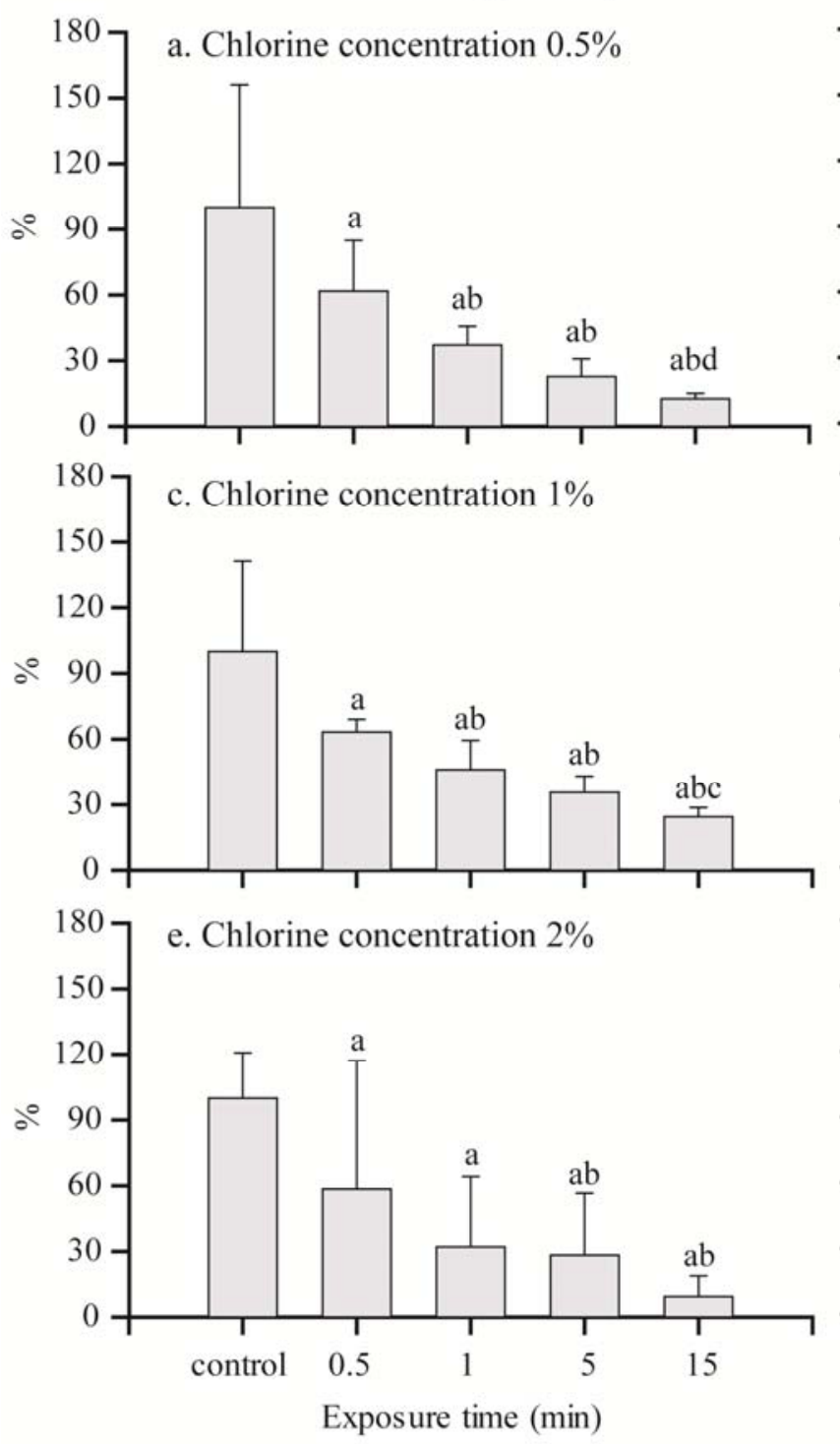

Chlorophyll $a$

b. Chlorine concentration $0.5 \%$

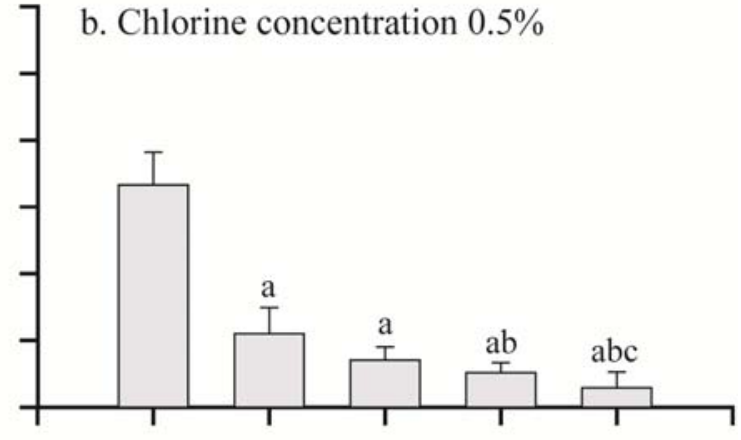

d. Chlorine concentration $1 \%$

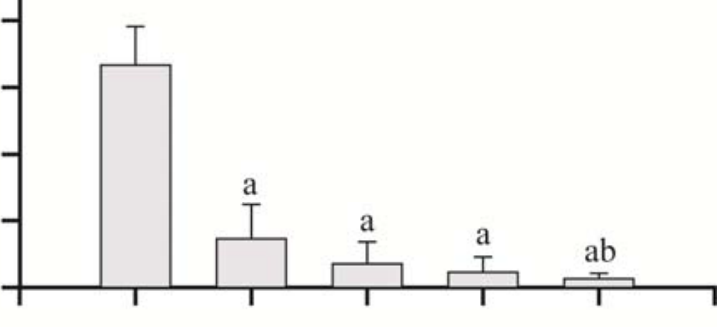

f. Chlorine concentration $2 \%$

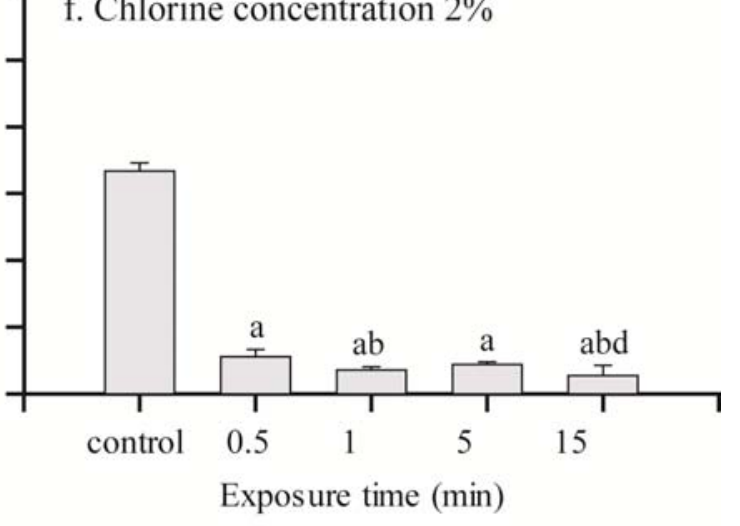

Figure 8 

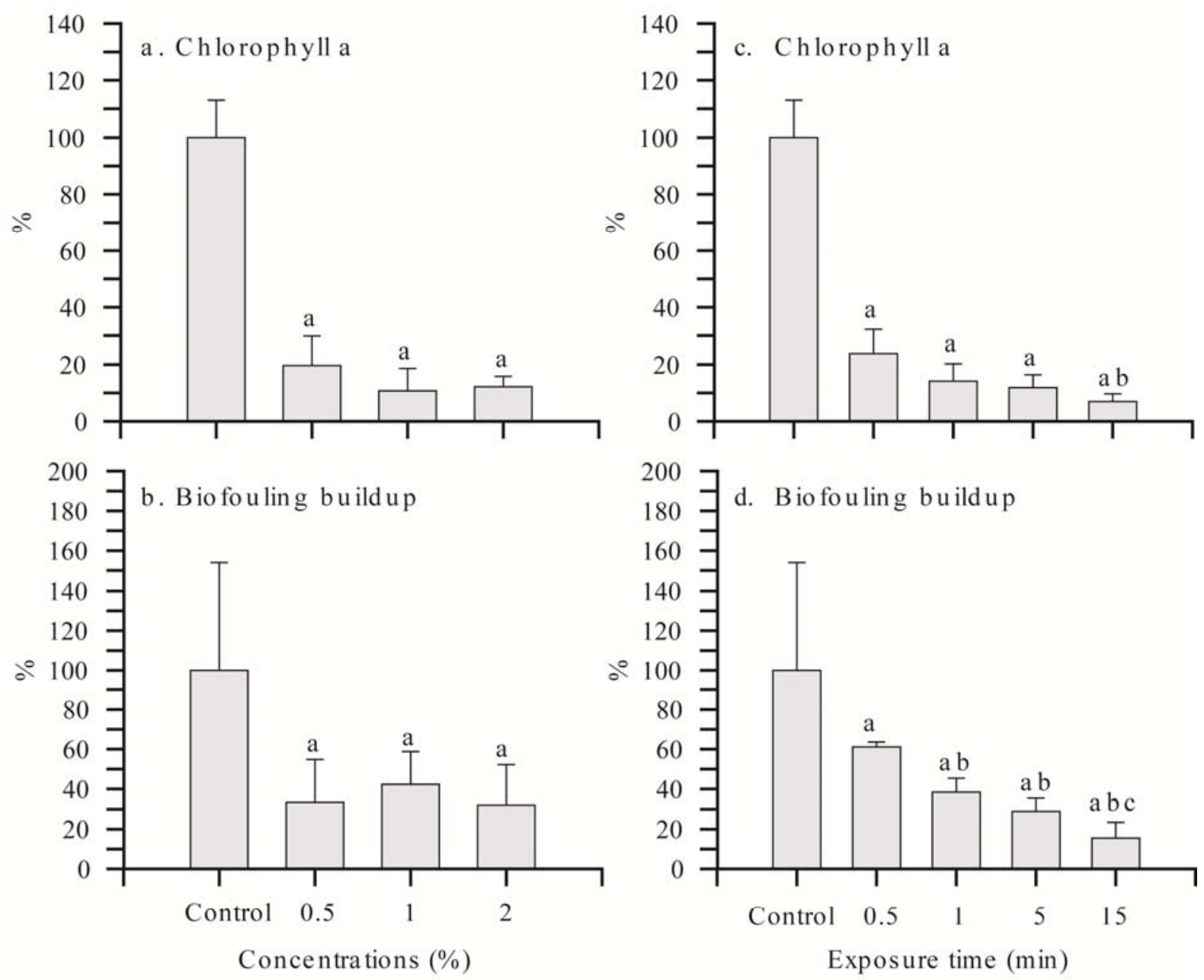

Figure 9 


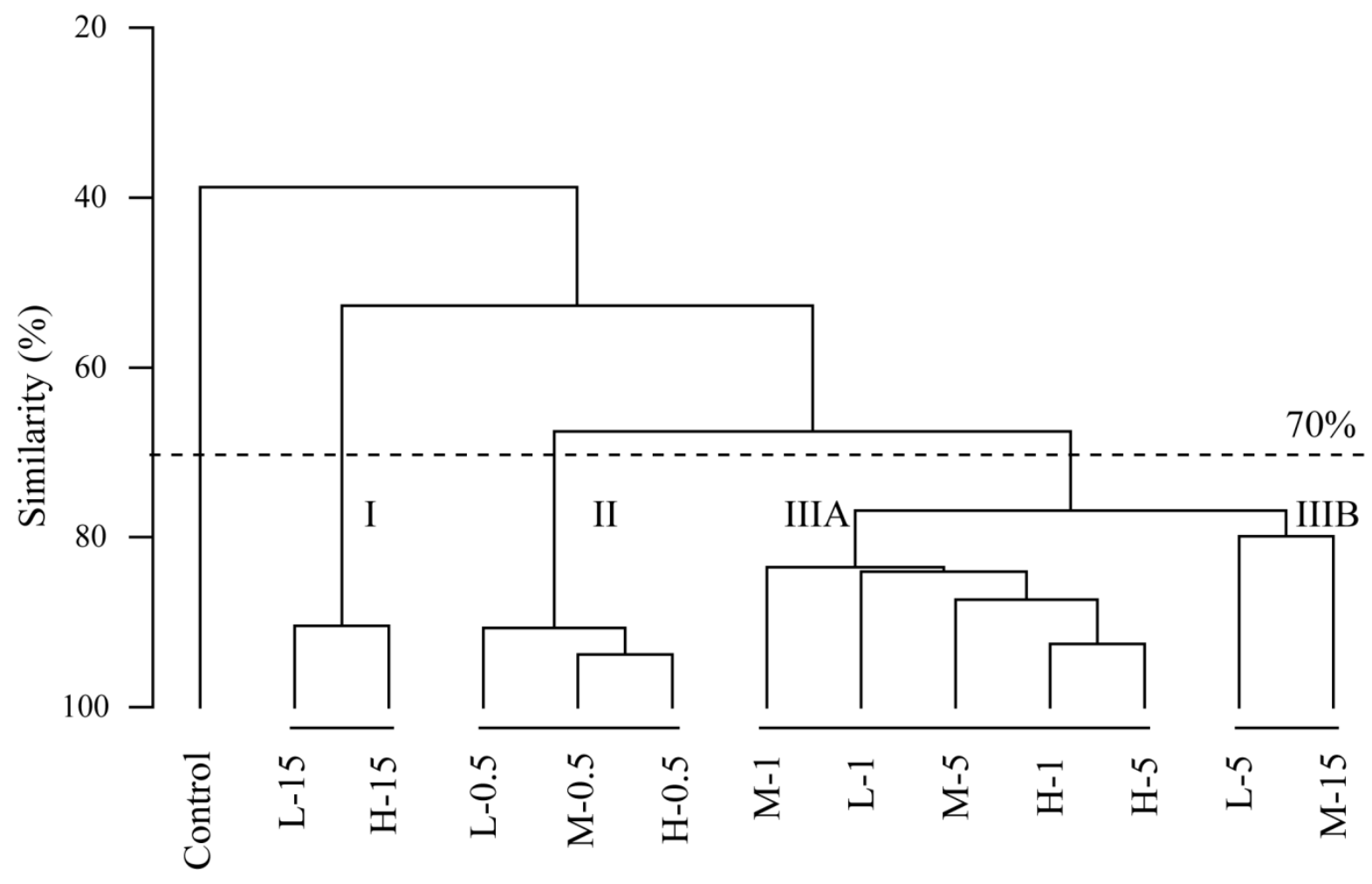

Figure 10 

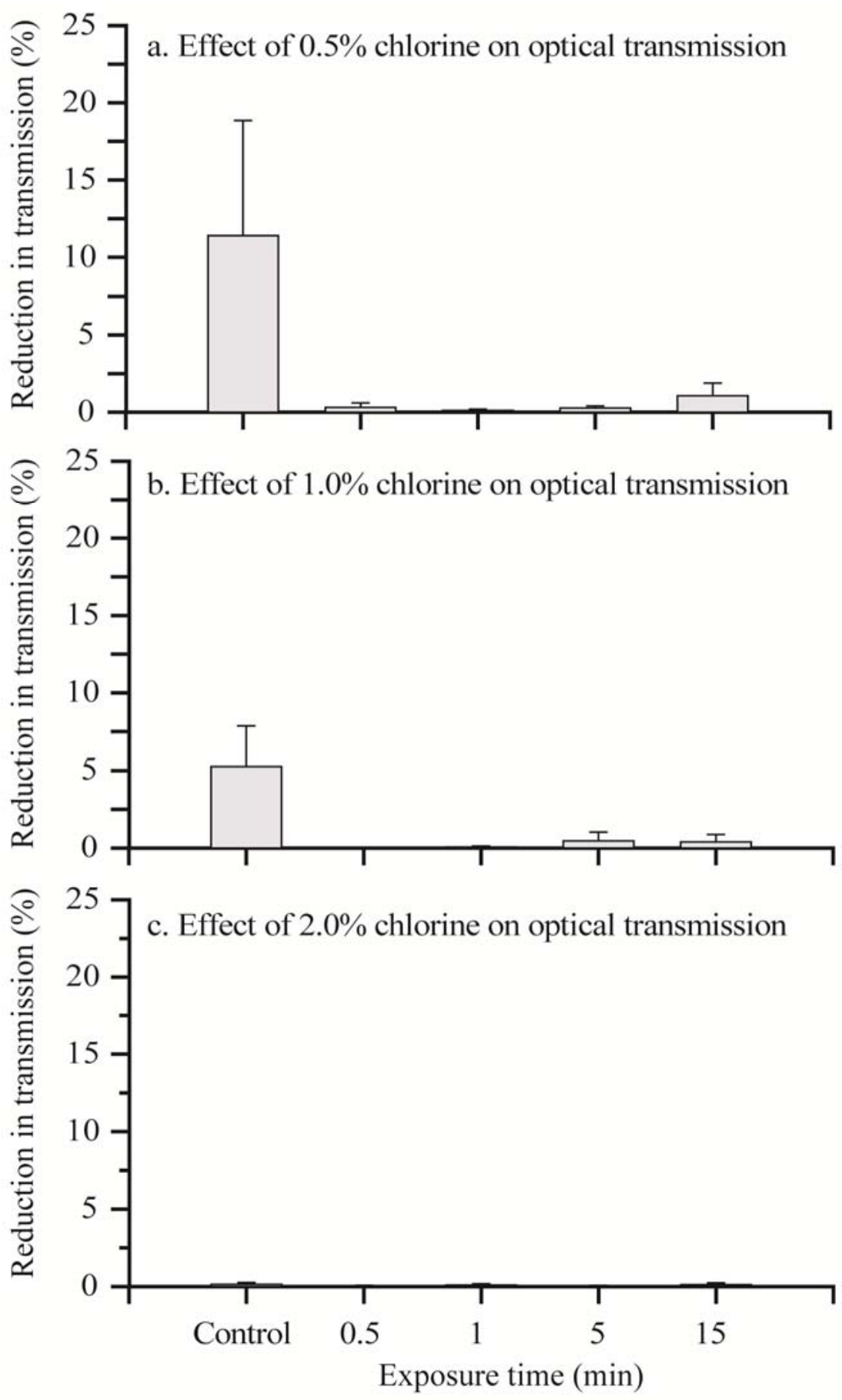

Figure 11 